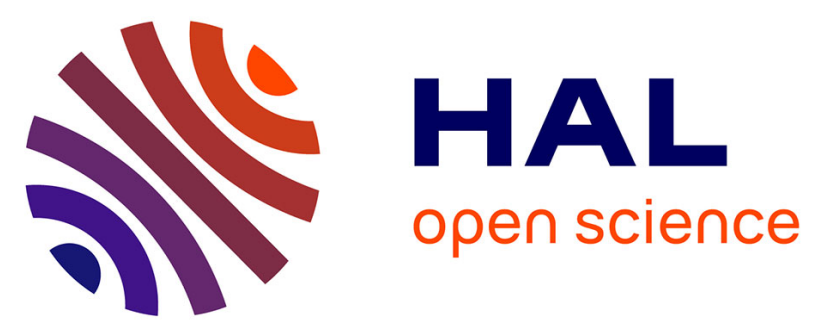

\title{
Phylogenetic relationships in the cricket tribe Xenogryllini (Orthoptera, Gryllidae, Eneopterinae) and description of the Indian genus Indigryllus gen. nov.
} Ranjana Jaiswara, Jiajia Dong, Tony Robillard

\section{- To cite this version: \\ Ranjana Jaiswara, Jiajia Dong, Tony Robillard. Phylogenetic relationships in the cricket tribe Xenogryllini (Orthoptera, Gryllidae, Eneopterinae) and description of the Indian genus Indigryllus gen. nov.. Journal of Zoological Systematics and Evolutionary Research, 2019, 57 (4), pp.789-805. 10.1111/jzs.12298 . hal-02453481}

\author{
HAL Id: hal-02453481 \\ https://hal.science/hal-02453481
}

Submitted on 23 Jan 2020

HAL is a multi-disciplinary open access archive for the deposit and dissemination of scientific research documents, whether they are published or not. The documents may come from teaching and research institutions in France or abroad, or from public or private research centers.
L'archive ouverte pluridisciplinaire HAL, est destinée au dépôt et à la diffusion de documents scientifiques de niveau recherche, publiés ou non, émanant des établissements d'enseignement et de recherche français ou étrangers, des laboratoires publics ou privés. 
1 Phylogenetic relationships in the cricket tribe Xenogryllini (Orthoptera, Gryllidae,

2 Eneopterinae) and description of the Indian genus Indigryllus gen. nov.

3

$4 \quad$ Page headlines: Phylogeny of Xenogryllini

5

$6 \quad$ Ranjana Jaiswara* $\left(1,2^{\dagger}, 3\right)$

$7 \quad$ Jiajia Dong* $(3,4)$

8 Tony Robillard (3)

9

10 1_Department of Biological Sciences, Indian Institute of Science Education and Research Mohali,

11 140306, Punjab, India

$122^{\dagger} \_$Department of Zoology, Panjab University, 160014, Chandigarh, India

13 3_ Institut de Systématique, Evolution et Biodiversité (ISYEB), Muséum national d'Histoire naturelle,

14 CNRS, Sorbonne Université, EPHE, 57 rue Cuvier, CP 50, 75231 Paris Cedex 05, France

15 4_College of Life Science, Shaanxi Normal University, 710119, Xi'an, Shaanxi, P.R. China

16

$17 *$ Ranjana Jaiswara and Jiajia Dong should be considered joint first authors

$18 \uparrow$ Present address

19 Corresponding author: Ranjana Jaiswara (ranjana.jaiswara@gmail.com) 
21 Subfamily Eneopterinae is known greatly for its diversified acoustic modalities and disjunct 22 distribution. Within Eneopterinae, tribe Lebinthini is the most studied group, due to its highest species 23 diversity ( $c a .150$ species in 12 genera), endemic distribution on the islands of Southeast Asia and of 24 the South West Pacific, males' ability to produce high-frequency calling songs and evolution of 25 females' vibrational response. To investigate the distribution pattern and diversification of acoustic 26 and behavioural attributes in a larger frame, clear understanding of phylogenetic relationships within 27 other tribes of Eneopterinae is vital. In this study, we focus on the tribe Xenogryllini, sister group of 28 Lebinthini. Xenogryllini, as opposed to Lebinthini, is known by fewer species (11 species in 2 genera), 29 distributed widely in continental Asia and Africa, and for producing low-frequency calling songs. We 30 describe a new genus Indigryllus with a new species of the tribe Xenogryllini, discovered from the 31 Southwest of India. We used eight genetic markers to reconstruct the phylogenetic relationships. The resultant phylogenetic tree is used to compare and discuss distribution patterns and acoustic modalities between Lebinthini and Xenogryllini.

34 


\section{INTRODUCTION}

The crickets of the subfamily Eneopterinae have been studied for the diversity of their communication signals and related structures (e.g., Robillard \& Desutter-Grandcolas 2004a, b; Robillard et al., 2013; ter Hofstede et al., 2015; Schneider et al., 2017), and for their biogeographical patterns (Nattier et al., 2011; Vicente et al., 2017; Dong et al., 2018). Most of these recent works have focused on the tribe Lebinthini, that shows the highest species diversity ( $c$ a. 150 species in 12 genera; Cigliano et al., 2019) and endemic distribution in the islands of Southeast Asia and South West Pacific. The Lebinthini have also developed an original system of communication involving female vibrational responses to male high-frequency calling songs and loss of phonotaxis (ter Hofstede et al., 2015). To investigate how this diversity emerged and how the original traits evolved, it is necessary to investigate the context in which it happened. Being the sister group of Lebinthini, the tribe Xenogryllini therefore is the best "control lineage" to better understand the evolution of unique features in Lebinthini. A taxonomic and phylogenetic focus on the Xenogryllini is thus particularly needed.

Tribe Xenogryllini is a group of crickets with contrasting features under subfamily Eneopterinae. It is currently known only by two genera, Xenogryllus Bolívar, 1890 (eight species) and Pseudolebinthus Robillard, 2006 (three species) according to recent revision works (Jaiswara et al., 2018 \& 2019). Unlike Lebinthini, members of Xenogryllini are distributed widely in continental regions, from Asia to Africa. Calling songs have recently been documented for five species of the genus Xenogryllus and is unknown for Pseudolebinthus (Jaiswara et al., 2018). As opposed to Lebinthini, Xenogryllini members produce calling songs with longer syllables and lower dominant frequencies. In the present study, we describe a new genus and a new species of Xenogryllini from South India, Indigryllus kudremu Robillard \& Jaiswara gen. nov. et sp. nov. and provide an emended key to Xenogryllini genera. Considering the recent advances in information with respect to species diversity, distribution and acoustic signals for Xenogryllini, this study focuses on establishing phylogenetic relationships among species of all three genera of the tribe. According to the resultant phylogenetic relationships we contrast Xenogryllini and Lebinthini in terms of species diversity, 
patterns of distribution and signals of communication. In the light of comparable taxonomic treatment, we assess whether Xenogryllini are truly less diversified than Lebinthini, as suggested earlier (Robillard \& Desutter-Grandcolas, 2004b). We then discuss how different are the distributions and calling songs of both tribes with respect to their parallel biogeographical history and evolution of an original system of communication in Lebinthini.

\section{MATERIAL AND METHODS}

\subsection{Taxonomy}

Specimens of Indigryllus kudrmu gen. nov. et sp. nov. come from a field work expedition in India (2007) and are deposited in the collections of Zoological Survey of India, Kolkata (ZSI) and Muséum national d'Histoire naturelle, Paris (MNHN). The descriptions of the new genus and species follow terminologies as proposed by Robillard et al. (2014). Observations of external morphological characters and dissection of male and female genitalia were performed using Leica stereomicroscopes MZ16. Terminologies for male forewing (FW) venation follow Ragge (1995) and Robillard \& Desutter-Grandcolas (2004b). Male and female genitalia were dissected from dry preserved specimens by making a small slit between paraproct and subgenital plate. Female copulatory papilla was dissected out by cutting the membrane between ovipositor and subgenital plate. Dissected genitalia were cleared in $10 \%$ cold $\mathrm{KOH}$ solution and preserved in glass vials containing glycerine. Terminologies for genitalia follow Desutter (1987), modified in Desutter-Grandcolas (2003) and Robillard \& Desutter-Grandcolas (2004a). Imaging of male and female genitalia were made using an AmScope MU1000 digital camera (www.Amscope.com) or with a Canon EOS 40D Digital SLR camera. To highlight the structural components of male and female genitalia, water solution containing a drop of JBL Punktol was used. To fix orientations and stabilization of genitalia for photography, a clear and viscous Power Plast Hand Sanitizer was used following Su (2016). 


\section{Abbreviations}

General morphology: FI, FII, FIII, fore, median, hind femur; FW, forewing; TI, TII, TIII, fore, median, hind tibia; Tarsomere I/II/III-1: basal segment of fore, median and hind leg tarsomere. alignment; $\mathrm{d} 2$, second cell of D alignment; e1, first cell of E alignment.

\subsection{Taxon sampling}

The tribe Xenogryllini is composed of three genera and 12 valid species: Xenogryllus Bolívar (8 species), Pseudolebinthus Robillard (3 species) and Indigryllus kudremu Robillard \& Jaiswara gen. nov. et sp. nov. ( 1 species). To reconstruct the phylogeny of the tribe Xenogryllini, a total of 20 individuals representing 8 species belonging to the three genera were sampled: Xenogryllus is represented by 6 species sampled for 1-4 populations per species (the species X. lamottei Robillard and X. maniema Robillard \& Jaiswara are represented by only old specimens which could not be sequenced); Pseudolebinthus is represented by one individual of $P$. gorochovi Robillard; Indigryllus by one individual of the species I. kudremu sp. nov.

For outgroup selection, we referred to a previous study (Anso et al., 2016) and selected 8 species representing all five tribes of the Eneopterinae subfamily, as well as two more distant species belonging to the subfamily Gryllinae. Whenever possible, we obtained DNA sequence data from the same previous voucher specimens. See Table 1 for detailed information about taxon and genetic markers. 


\subsection{DNA markers, PCR amplification and sequence alignment}

114 We used DNA markers from eight genes, five from the mitochondrial and three from the nuclear genome based on previous studies (Robillard \& Desutter-Grandcolas, 2006; Nattier et al., 2011, 2012 \& 2013; Chintaun-Marquier et al., 2016). The mitochondrial markers were partial sequences of the $12 S$ rRNA gene $(12 S$, amplicon $\sim 400 \mathrm{bp})$, the $16 S$ rRNA gene $(16 S, \sim 500 \mathrm{bp})$, of the cytochrome $b$ gene $(C y t b, \sim 400 \mathrm{bp})$, and of the cytochrome c oxidase subunit $1(\mathrm{CO} 1, \sim 750 \mathrm{bp})$ and subunit $2(\mathrm{CO}$, $\sim 400 \mathrm{bp}$ ). Nuclear markers were partial sequences of protein coding histone $H 3$ gene (H3, $330 \mathrm{bp})$, and partial sequences of two non-protein-coding genes corresponding to nuclear ribosomal subunits $18 S$ rRNA (18S, $650 \mathrm{bp})$ and $28 S$ rRNA $(28 S, \sim 400 \mathrm{bp})$.

DNA extraction, PCR amplification and sequencing for all studied taxa, except for three Indian X. transversus samples, were carried out at Service de Systématique Moléculaire of the MNHN, following the protocols as described in Nattier et al. (2012). For the Indian X. transversus specimens Services (Base Asia). cleaned and checked for sequencing errors in Sequencher v.4.9 (Gene Codes Co.) and BioEdit v.7.0.5.3 (Hall, 1999), then blasted with NCBI blast tools, and submitted to GenBank (Table 1). The

131 CO1 sequences of X. marmoratus specimens were discarded because of the suspicion of pseudogenes.

132 The sequences were aligned with MAFFT version 7 online (Kuraku et al., 2013; Katoh et al., 2017).

133 The complete combined dataset consists of 3,684 aligned base pairs (bp) for a total of 35 terminals 134 available as supplementary material S1: 416 bp for $12 S, 521$ bp for $16 S, 707$ bp for CO1, 335 bp for $135 C O 2,346$ bp for $C y t b, 328$ bp for $H 3,652$ bp for $18 S$ and 379 bp for $28 S$. 


\subsection{Phylogenetic analyses}

138 Preliminary phylogenetic analyses were carried out for each DNA marker to check for possible 139 contaminations and artifacts, using the IQ-TREE web server (http://iqtree.cibiv.univie.ac.at/; 140 Trifinopoulos et al., 2016). The aligned sequences of all eight markers were further concatenated in 141 Geneious R9.0.2 (Biomatter Ltd., New Zealand, www.geneious.com, Kearse et al., 2012).

The concatenated dataset was analyzed using Bayesian inference (BI) and maximum likelihood 143 (ML). For both BI and ML, PartitionFinder V2.1.1 (Lanfear et al., 2017) was used to determine the 144 best-fit partitioning schemes and the associated substitution models. One partition was specified for each of the non-protein-coding genes $(12 S, 16 S, 18 S$ and $28 S)$ and one partition per codon for the protein-coding genes ( $\mathrm{CO}, \mathrm{CO} 2, \mathrm{Cyt}$ and $\mathrm{H} 3$ ). PartitionFinder analyses were carried out using the default 'greedy' algorithm option and either the 'mrbayes' or 'raxml' set of models (for BI and ML analyses, respectively). The Bayesian information criterion (BIC) was preferentially used to compare partitioning schemes and substitution models following Ripplinger and Sullivan (2008). on the CIPRES Science Gateway 3.3 (Miller et al., 2015) web portal. random-addition replicates. Clade support was assessed using non-parametric bootstrap; for each analysis 1,000 bootstrap replicates were conducted. Nodes supported by bootstrap support values (BS) $\geq 70 \%$ were considered strongly supported following Hillis and Bull (1993).

158 (MCMC): one cold and seven incrementally heated that ran for 50 million generations with trees 159 sampled every 1,000 generations. We used a conservative burn-in of 12.5 million generations per run 160 after checking for stability on the log-likelihood curves and the split-frequencies of the runs in Tracer 161 v.1.7 (Rambaut et al., 2014). Support of nodes for MrBayes analyses was provided by clade posterior 
probabilities (PP) as directly estimated from the majority-rule consensus topology. A clade with a PP

163 value higher than 0.95 was considered as well supported following Erixon et al. (2003).

\section{RESULTS}

166

167

168

169

170

171

172

173

\subsection{Phylogenetic results}

The complete DNA sequence matrix comprises 3,684 base pairs sampled for 35 terminals (Table 1 and Supporting information S1). The separate ML analyses of each DNA marker show no major conflict in topology (see Supporting information S2).

The best-fit partition schemes and substitution models used in BI and ML analyses of the combined datasets are showed in Supporting information (S3). Both BI and ML phylogenetic analyses yielded robust and largely congruent topologies (Fig. 7, see also Supporting information S4 for original outputs of both BI and ML analyses).

In both analyses, the subfamily Eneopterinae and the tribe Xenogryllini are recovered as monophyletic with high support values (PP of 1.0 and BS of 100\% for Eneopterinae, and PP of 1.0 and BS of $99 \%$ for Xenogryllini). The sister relationship between tribes Lebinthini and Xenogryllini is strongly supported by the ML analysis (BS of 93\%), but not by the BI analysis, where the tribe Lebinthini is paraphyletic, with the Xenogryllini being sister of the main clade of the Lebinthini with low PP value (0.68).

Within the tribe Xenogryllini, all species are recovered as monophyletic. In both analyses, Xenogryllus is recovered as sister of Indigryllus (BS of $100 \%$ and PP of 1.0), and this clade is sister to Pseudolebinthus (BS of 99\% and PP of 1.0). Within Xenogryllus, the species X. mozambicus and X. eneopteroides from Africa form a well-supported clade in both BI and ML analyses (PP of 1.0 and BS of $100 \%$ ); they form the sister group of a clade including the remaining species distributed in Asia. In the latter clade, except for well-defined position of X. marmoratus (BS of $80 \%$ and PP of 1.0) as sister to the other species, the positions of $X$. transversus, $X$. maichauensis and $X$. ululiu are not wellsupported: In BI analysis, X. transversus is found as the sister species of the clade $(X$. ululiu $-X$. 
maichauensis), while the ML analysis finds $X$. maichauensis as the sister species of ( $X$. transversus X. ululiu).

\subsection{Systematics}

\subsubsection{Key to Xenogryllini genera modified from Robillard (2006)}

1. TII with two inner apical spurs. FWs and hind wings of similar dimensions in male and female

195 differentiated, pointed B).

\section{Robillard, 2006}

(Fig.1). Male. Forewing venation (Fig. 3A-B): left and right forewings similar in sclerotization and colouration; harp oblique veins not swollen, with an incomplete oblique between diagonal and first complete oblique; harp distal angle concave; FWs cells with thin longitudinal wrinkles on surface. Male genitalia: pseudepiphallic sclerite longer than rami (Fig. 4); basis of pseudepiphallus sclerotized (Fig. 4A); ectophallic arc not sclerotized; ectophallic fold entirely sclerotized; lateral arms of endophallic sclerite very long (Fig. 4B); endophallic crest absent. Female. FWs and hind wings as long as in male. Ovipositor apex well differentiated, rounded (Fig. 6A2 .

- TII with one inner apical spur. Male with longer FWs than female, hind wings absent in both sexes. Male. Forewing venation: left FW less sclerotized than right FW; harp with swollen oblique veins, without an incomplete vein between diagonal and first harp vein; harp distal angle flat; FW cells without longitudinal wrinkles. Male genitalia (Fig. 5D): pseudepiphallic sclerite shorter than rami, basis of pseudepiphallus membranous; ectophallic arc slightly sclerotized; ectophallic fold partly sclerotized; lateral arms of endophallic sclerite short; endophallic crest absent. Female. FWs very short, not reaching second abdominal tergite; hind wings vestigial. Ovipositor apex little Pseudolebinthus 
213 2. Eyes small and located on face (Fig. 2D-F). FIII narrow along its whole length. FWs as long or 214 slightly longer than abdomen in both sexes. Hind wings longer than FWs, forming a tail posterior to 215 FWs. Male. Male genitalia: Pseudepiphallic paramereres with one strong rectangular ventral lobe 216 covered with scale-like sculptures (Fig. 5B-C). Female. Apex of ovipositor spatula-shaped (Fig. $6 \mathrm{~B})$ Xenogryllus Bolívar, 2181890 - Eyes larger and lateral (Fig. 2A-C). FIII wide basally, muscular. FWs reaching abdomen mid-length, hind wings vestigial. Male. Male genitalia: Pseudepiphallic paramereres with two short claw-shaped sclerotized lobes ventrally (Fig. 4D). Female. Apex of ovipositor triangular (Fig. $6 \mathrm{~A})$ .Indigryllus Robillard \& Jaiswara gen. nov.

3.2.2. Indigryllus Robillard \& Jaiswara gen. nov.

Type species.

Indigryllus kudremu Robillard \& Jaiswara sp. nov.

\section{Etymology}

230 The genus name is derived from India and the suffix - gryllus in reference to the name Xenogryllus.

\section{Diagnosis}

Indigryllus presents all the characteristics of Xenogryllini, but majorly shares a combination of morphological features of Xenogryllus and Pseudolebinthus (Fig. 1A-D). The new genus resembles Pseudolebinthus by shape of head and eyes, brachypterous wings barely reaching abdomen mid-length in males, shorter in females (but longer in Indigryllus than in females of Pseudolebinthus), muscular FIII (thinner in Xenogryllus), and long, rather slender abdomen. Indigryllus is however more similar to 
238 Xenogryllus in terms of size, homogeneous light brown colouration, male FWs symmetry, without 239 swellings of harp veins as in Pseudolebinthus, and male genitalita with long sclerotized 240 pseudepiphallic lophi (Fig. 5A).

\section{Description}

243 Size average for the tribe. Head shape (Fig. 2A-C) close to that of Pseudolebinthus and tribe 244 Lebinthini, with eyes larger and more protruding than in Xenogryllus. In dorsal view (Fig. 2A), eyes 245 combined width represents ca. 45\% of head width, as for example in Macrobinthus Robillard \& Dong, 246 2016. Head slightly higher than wide in facial view (Fig. 2B); face with a whitish mask with black 247 spots as in Xenogryllus, underlined laterally with a dark line prolonged on eyes; flat in lateral view 248 (Fig. 2C). Fastigium twice as wide as scape, almost square, slightly divergent apically, not 249 discontinuous from vertex nor furrowed longitudinally; fastigium twice as wide as scape, with many 250 setae up to median ocellus. Ocelli flat, arranged in a wide triangle; lateral ocelli almost circular, 251 located at basis of fastigium; median ocellus ellipsoidal, subapical in location. Scape small. Antennae 252 thin. Maxillary palpi long, their 5th joint as long as 3rd and slightly widened apically. Pronotum dorsal 253 disc slightly wider than long, posterior margin straight; lateral margins not carinated. TI with two 254 tympana; inner tympanum covered by a sclerotized expansion, its membrane visible along a small 255 longitudinal slit only; outer tympanum oval in shape, its surface smooth. TI with two inner and two 256 outer apical spurs. TII with two inner spurs of equal lengths, and two outer spurs, the dorsal the 257 longest. FIII apex filiform, their bases muscular, wider than in Xenogryllus. TIII serrulated over their 258 whole length, slightly furrowed dorsally, with four pairs of subapical spurs and three pairs of apical 259 spurs; inner and outer spurs (both subapical and apical) of almost similar size, straight and slightly curved apically. Abdomen long and slender, conical.

261 Male. Metanotal glandular structures well developed, similar to that of Xenogryllus, with a large 262 median process on scutum, scutellum raised medially and carrying a bunch of setae oriented 263 anteriorly. Posterior part of mesonotum setose and extended posteriorly, covering metanotal scutum. 264 Hind wings shorter than the FWs. FWs short (Fig. 3A-B), reaching two thirds of abdomen length, 
symmetrical, not widened as in Xenogryllus. FW cells with longitudinal wrinkles as in Xenogryllus.

266 FWs light brown, translucent, with the following pattern of black spots on dorsal field: wide black

267 transverse band anterior to transverse part of $1 \mathrm{~A}$, black marking in cell $\mathrm{c} 1$ and in anterior and external

268 corners or mirror. Harp wide, oblique veins as in Xenogryllus, with two complete bisinuate veins and

269 one incomplete vein posteriorly. Mirror large and rounded, as in Xenogryllus, crossed at mid-length by

270 a complete accessory vein. Cell d2 widened. Apical field short, including four narrow cell alignments.

271 Lateral field crossed by numerous projections of Sc along its whole length, as in Xenogryllus.

272 Subgenital plate clog-shaped, its apex slightly indented.

273 Male genitalia (Fig. 4A-D). Close to Xenogryllus, with long sclerotized pseudepiphallic lophi (Fig.

274 5A), their apex with a short inner hook-shaped dorsal expansion. Membrane at anterior basis of 275 pseudepiphallus slightly sclerotized, as in Xenogryllus; anterior margin of pseudepiphallus 276 strengthened by a ventral sclerotization. Rami rather short and strong, their apex slightly convergent.

277 Pseudepiphallic parameres strong, with a strong dorsal lobe and two ventral lobes clearly 278 individualised (Fig. 4D); surface of parameres thinly denticulate. Ectophallic fold homogeneously 279 sclerotized. Ectophallic arc not sclerotized, as in Xenogryllus; ectophallic apodemes long, lamellate 280 apically; their basis with strong ventral arms. Endophallic sclerite forming a wide flat plate rounded 281 anteriorly, with long thin lateral arms oriented posteriorly and a long medio-posterior expansion fused 282 with ectophallic fold. Endophallic apodeme with a thin dorsal median crest and narrow lateral 283 lamellas.

284 Female. FWs shorter than in males (Fig. 3C), not reaching abdomen mid-length; colouration pale 285 brown; dorsal field with six strong longitudinal veins; lateral field triangular; $\mathrm{M}$ vein faint; R/Sc area 286 wide, brown with faint transverse veins; Sc with two projections. Subgenital plate slightly indented apically (Fig. 6C). Apex of ovipositor rounded and smooth, more pointed than in Xenogryllus (Fig. 288 6A).

289 Female genitalia. Copulatory papilla (Fig. 6E-G) more elaborate than in Xenogryllus, with a wide 290 cylindrical basal part sclerotized ventrally, and a narrowed cylindrical apical membranous part, thinly 291 plicate and slightly folded ventrally. 


\subsubsection{Indigryllus kudremu Robillard \& Jaiswara sp. nov.} The species is named after the type locality.

(Figs 1A-D; 2A-C; 3B-C; 4A-D; 5A; 6A, C, E-G; 7) phylogeny); 2006: 644. (historical biogeography).

\section{Type material}

\section{Type locality}

India, Karnataka, Chikkamagaluru district, Kudremukh.

\section{Etymology}

Xenogryllus n. sp. - Robillard \& Desutter-Grandcolas, 2004a: 579; 2004b: 275 (morphological

Xenogryllus sp. - Nattier et al., 2011: 2201 (molecular phylogeny); Vicente et al., 2017: 2203

Holotype, ô, India: Kudremukh, 29.V.2007 KWC-93-00.229, identified Xenogryllus marmoratus S. Rawat \& R. Balakrishnan (ZSI). Allotype, 우, India: Same locality, date and collector as HT, KCW92-00.228, identified Xenogryllus sp. by R. Balakrishnan, lab code for molecular sample X3Xsp2 (ZSI). Paratype (l $\hat{o})$, India: same locality, date and collector as HT, NCW-0230, identified Xenogryllus carmichaeli? by R. Balakrishnan, identified Xenogryllus sp. by T. Robillard, MEB cerque g., lab code for molecular sample Xsp (MNHN-EO-ENSIF2738).

\section{Diagnosis}


Indigryllus kudremu sp. nov. is recognized by its light colouration, brachypterous wings in both sexes,

317 long abdomen, and male genitalia with pseudepiphallic lophi forming two blades partly fused basally

318 (Fig. 5A), close to that of X. marmoratus, converging basally, their apex diverging, with a short hook319 shaped dorsal expansion.

\section{Description}

322 In addition to the characters of the genus, colouration mostly ochre (Fig. 1A-D); vertex with four faint 323 longitudinal brown bands and two triangular lines posterior to eyes (Fig. 2A). Scapes with dark brown 324 patterns; antennae uniformly yellow brown, except first article dark brown. Pronotum dorsal disc light 325 brown, mottled with orange brown; pronotum lateral lobes almost homogeneously golden brown with 326 black dots, dorsal margin underlined with dark brown; anterior ventral corner with a yellow spot; 327 posterior margin mottled with yellow and dark brown. FI-II yellow brown mottled with dark brown; 328 TI-II and Ta-I-II yellow dark brown apically. FIII almost homogeneously orange brown. Abdomen 329 light brown mottled with black, whitish ventrally. Cerci long, their inner face dark, rest light brown.

330 Male. FWs mostly light brown (Fig. 3B), veins light brown or yellow; anterior dark brown colouration 331 on dorsal field including whole width of 1A. Apical field with yellow brown longitudinal veins and 332 strong dark brown transverse veins. Lateral field with 12-14 $(\mathrm{n}=2)$ projections of Sc and 3-6 more 333 ventral veins.

334 Male genitalia (Fig. 4A-D). Pseudepiphallic lophi long (Fig. 5A), setose, curved dorsally in lateral 335 view, forming two blades partly fused basally, converging at mid-length then diverging apically; apex 336 of lophi with short inner hook-shaped dorsal expansions.

337 Female. Ovipositor short, about half of FIII length.

338 Calling song. Unknown.

339 Measurements. See Table 3. 


\section{Distribution and natural history}

342 The type locality is in the west of the Western Ghats, one of the evergreen forests in India. Since the 343 species was never found again in the same or close-by areas therefore, we hypothesize that the type 344 locality does not correspond to the natural habitat of the species.

The type specimens were found in a backyard garden that had diverse plantation, but was dominated by areca nuts. The garden was least managed and had pineapple, hibiscus, paper mulberry and other shrubs. The specimens were collected during the monsoon season when the average temperature ranges between 25 to $37^{\circ} \mathrm{C}$ and average humidity is $c a .77 \%$.

\section{DISCUSSION}

\subsection{Diversity and distribution of the Xenogryllini}

The taxonomic revision of the Xenogryllini achieved in Jaiswara et al. $(2018,2019)$ and completed here by the description of the new genus Indigryllus, was based on the thorough study of specimens from natural history collections belonging to 17 institutions and on field work in Mozambique, China and India. These studies reveal that the Xenogryllini tribe is relatively less diversified compared to the other tribes of the subfamily Eneopterinae, and more specifically to its sister tribe, the Lebinthini. The taxonomic revisions clarified the status of all previously described species and subspecies and added five new species to the Xenogryllini: three to Xenogryllus (Jaiswara et al., 2019), one to Pseudolebinthus (Jaiswara et al., 2018), and the new genus Indigryllus with one new species from Southern India. The combination of these three studies allows drawing a map of distribution for all the species of the Xenogryllini (Figure 8).

The discovery of Indigryllus is particularly relevant to improve the knowledge of eneopterines.

364 First, it is the first record of Eneopterinae in the southern half of India. Until now, eneopterines were 365 represented in the region only by some populations of $X$. transversus distributed in Northern and 366 Eastern India and in Pakistan (Bhowmik, 1976, 1985; Saeed et al., 1990). Second, Indigryllus shows 
original combination of characters from the other two genera of the tribe: it is brachypterous with long abdomen and large eyes as Pseudolebinthus, while its male genitalia and FW venation are clearly more similar to that of Xenogryllus. As mentioned in the taxonomic part, I. kudremu sp. nov. is documented by three specimens only, collected once, and the type locality belongs to the west of the Western Ghats, one of the evergreen forests in India. Since the species was never found again in the same area, we hypothesize that its type locality may not correspond to the natural habitat of the species. The Western Ghats is one of the biodiversity centres in India; therefore, it has been a focus region for numerous recent faunal discoveries in diverse groups such as frogs, birds, shield tail snakes and lizards (e.g., Kuramoto \& Joshy, 2003; Giri et al., 2004; Biju \& Bossuyt, 2005, 2009; Biju et al., 2009; Robin et al., 2017; Jins et al., 2018; Sadasivan et al., 2018; Raj et al., 2018; Agarwal et al., 2018). In the last two decades, only a handful of new cricket species belonging to Gryllidae,

378 Phalangopsidae and Pteroplistinae have been described (Gorochov, 2002, 2003, 2009, 2018; Desutter-

379 Grandcolas \& Jaiswara, 2012; Jaiswara \& Desutter-Grandcolas, 2014). Present discovery of 380 Indigryllus suggests that the region of the Western Ghats may still keep some undescribed lineages of crickets.

\subsection{Phylogenetic relationships and biogeographical patterns}

The molecular phylogenetic analysis confirms the monophyly of the tribe Xenogryllini with a high support, and its sister relationship with the Lebinthini tribe. These results are consistent with the previous phylogenetic analyses based on a lower Xenogryllini sampling with morphological (Robillard \& Desutter-Grandcolas, 2004a; Robillard, 2006) and DNA sequence data (Nattier et al., 2011; Vicente et al., 2017). The paraphyly of the Lebinthini found in the BI analysis is probably due to low taxonomic sampling of this tribe in our study, since the Lebinthini are clearly monophyletic and distinct from the Xenogryllini in all previous phylogenetic studies, as recovered by our ML analysis. 
partly addressed, but shortly discussed, in the study of Vicente et al. (2017). The study included

395 representatives from the three Xenogryllini genera (Indigryllus kudremu was identified as 396 "Xenogryllus sp." and Peudolebinthus gorochovi as "Pseudolebinthus sp."). The study also dated the 397 stem group of the Xenogryllini, revealing the split between Xenogryllini and Lebinthini ca. 59.64 Ma, 398 and the Xenogryllini crown group $c a .52 .35$ Ma. The results of the ancestral area reconstructions 399 suggested an origin of Xenogryllini both in Asia and India (DEC results), suggesting that Africa was 400 colonized twice independently by the Xenogryllini after 50 Ma: once by Pseudolebinthus and once by 401 Xenogryllus eneopteroides, which was the only species of the genus distributed in Africa at the time of 402 this study. The new lineages of Xenogryllini recently described, including three new species of 403 Xenogryllus from Africa and the additional information concerning the geographical distribution of the 404 tribe, question these conclusions. In particular, among the new species of Xenogryllus, X. lamottei 405 Robillard, 2018, more ressembles morphologically the species distributed in Asia (no lateral carinae 406 on pronotum, shape of pseudepiphallic lophi of male genitalia). It suggests an alternative 407 biogeographic scenario, involving an early colonization of Africa by the Xenogrillini and a later 408 independent recolonization event of India and of continental Southeast Asia by Indigryllus and by a 409 clade of Xenogryllus. Since several new species including X. lamottei could not be included in our 410 phylogenetic study, the biogeographic hypothesis could not be tested. The biogeographic history of the 411 Xenogryllini will have to be revisited by considering these new data into account in order to address specifically the routes and timing of colonization between Asia and Africa.

\subsection{Comparison between tribes Xenogryllini and Lebinthini}

415 The recent systematic revision of the Xenogryllini (Jaiswara et al., 2018 \& 2019) highlights several 416 interesting contrasts between the Xenogryllini and its sister tribe, the Lebinthini, in terms of species diversity, distribution patterns and signals of communication.

As hypothesised by Robillard \& Desutter-Grandcolas (2004a), there is a taxonomic imbalance 419 between the two tribes. The species ratio Lebinthini / Xenogryllini was 34/7 in 2004, but the recent 420 taxonomic discoveries in both clades changed drastically this ratio: with a similar taxonomic 
421 treatment, the Xenogryllini now includes a total of 12 species under 3 genera, whereas the Lebinthini

422 include $c a .150$ species under 12 genera (e.g., Robillard et al., 2014; Vicente et al., 2015; Anso et al., 423 2016; Robillard et al., 2016; Robillard \& Su, 2018), and many Lebinthini taxa yet remain undescribed 424 (T. Robillard, pers. obs.). This contrast is corroborating the hypothesis that the Lebinthini were likely subject to a taxonomic radiation, possibly in relation with their innovations in terms of communication system (Robillard et al., 2007).

Xenogryllini and Lebinthini are also contrasted in terms of distribution patterns. The Xenogryllini are mostly distributed in continental regions, except for X. marmoratus which is found both in continental Asia (China, South Korea) and in islands of Japan, China (Taiwan, Hainan) and Sri Lanka (Fig. 8). In contrast, the Lebinthini fully express their species diversity when they are distributed in islands (e.g., Desutter-Grandcolas \& Robillard, 2006; Nattier et al., 2012; Dong et al., 2018). As a consequence, the two tribes only barely overlap in their marginal distributions in coastal regions of China and Japan, where a few Lebinthini occur in sympatry with $X$. marmoratus. In association with this difference of tribe distribution, the species of the tribes differ by their range sizes: the Xenogryllini species, and in particular that of Xenogryllus, show relatively large distribution areas. This feature may be due to their continental distribution and the fact that they live in open habitats. In contrast, very high rates of speciation have been demonstrated in crickets distributed on islands (Mendelson \& Shaw, 2005). The Lebinthini species living on islands are most often found in forested areas; they also usually have more restricted distributions, which could in turn promote higher rates of speciation (Dong et al., 2018). These differences could partly explain the imbalance of diversity observed between the two tribes. However, exceptions exist, as for example the Lebinthini species Cardiodactylus novaeguineae (Haan, 1842), which lives in open coastal areas and shows a very large distribution across the Western Pacific (Robillard \& Ichikawa, 2009).

The last factor distinguishing Xenogryllini and Lebinthini are their modalities of communication, which are understudied in the Xenogryllini. The calling songs of five Xenogryllus species were recently formally described (Jaiswara et al., 2019), but that of Indigryllus and Pseudolebinthus species remain unknown. It would thus be erroneous to pretend that the Xenogryllini 
are characterized by calling songs made of long syllables with relatively low frequencies, since these

449 features are probably linked with the peculiar morphology of the males of Xenogryllus, which present 450 widened FWs and long stridulatory files carrying a high number of teeth, two characteristics favoring 451 the production of long syllables and low frequencies. The two other Xenogryllini genera, Pseudolebinthus and Indigryllus, were never acoustically recorded, and although very particular in 453 their own ways, they do not share these morphological features of Xenogryllus. It is thus impossible 454 yet to predict the features of their calling songs, except that they are probably different from that of 455 Xenogryllus. Comparatively, the songs of the Lebinthini are generally characterised by shorter syllables and high dominant frequencies. These acoustic features participate to a new system of communication which was recently described, involving absence of female phonotaxis and female vibratory response to male calls (ter Hofstede et al., 2015). These differences, and in particular the innovations allowing the Lebinthini to use new communication resources as key innovations in a context of adaptive radiation, has been proposed as a possible explanation for the imbalance of diversity observed between the two tribes (Robillard \& Desutter-Grandcolas, 2004a). Now that both tribes were subject to comparable taxonomic revisions, the hypothesis of adaptive radiation will have to be formally tested in future studies by estimating rates of speciation, extinction and adaptive phenotypic evolution using comparative phylogenetic methods (e.g., Herrera, 2017).

467 We acknowledge the Indo-French Centre for Promotion of Advanced Research (CEFIPRA) for 468 funding this project (PIs: Rohini Balakrishnan \& Laure Desutter-Grandcolas), and the National 469 Biodiversity Authority of the Government of India for providing the necessary permits to allow us to carry out the fieldwork. We owe our thanks to Professor Rohini Balakrishnan for bringing to our 471 attention the existence of unknown Eneopterine in India. We thank gratefully to the Director of IISER 472 Mohali, Professor N. Sathyamurthy, Dr. Manjari Jain and Professor Anand K. Bachhawat for hosting $473 \mathrm{RJ}$ as postdoctoral fellow and providing necessary infrastructure to carry out the research work. We 474 also thank the Orthopterist Society for supporting RJ with one-month project grant to visit MNHN in 
475 2017. The collaboration between France and China was facilitated by CAMPUS FRANCE and the 476 program PHC XU GUANGQI (2012). Part of this work was conducted in the context of the PhD 477 thesis of JD, which was funded by China Scholarship Council (CSC), the Innovation Funds of 478 Graduate Programs of Shaanxi Normal University [2012CXB019], the National Science Foundation of 479 China [Grant No. 31402006] and a supporting grant from "La Société des Amis du Muséum" and 480 ISYEB. Laboratory access and assistance was provided by the "Service de Systematique Moleculaire" 481 of the Muséum national d'Histoire naturelle, Paris (CNRS UMS 2700). The molecular work was 482 partly supported by agreement no. 2005/67 between the Genoscope (Evry, France) and the MNHN 483 project 'Macrophylogeny of life'; sequencing was also undertaken in the project @ SpeedID proposed 484 by F-BoL, the French Barcode of life initiative and the network 'Bibliothèque du vivant' funded by 485 the CNRS, INRA and MNHN, and through several MNHN grants (ATM "Génomique et collections"; 486 ATM blanche). We thank Andrej Gorochov (ZIN), Sigfrid Ingrisih (ZFMK), Hojun Song (Univ. 487 Texas) for providing samples for the molecular phylogeny. We also thank Simon Poulain (MNHN) for 488 his help photographing the specimens, and Karen Salazar (MNHN) for her help with line drawing 489 figures. We thank Jean-Yves Rasplus (CBGP, Montpellier) and Oliver Pascal for organising the 2009 490 expedition in Mozambique; this expedition was made possible by generous contributions from the 491 Prince Albert II of Monaco Foundation and the Stavros Niarchos Foundation; we would like to thank 492 Pro-Natura International and the Muséum national d'Histoire naturelle, Paris, for organising the 493 expedition under their Our Planet Reviewed programme, and the Instituto de Investigação Agrária de 494 Moçambique for helping with the administration and the collecting permits issue. 


\section{REFERENCES}

497

498

499

500

501

502

503

504

505

506

507

508

509

510

511

512

513

514

515

516

517

518

519

520

521

Agarwal, I., Khandekar, A., Ramakrishnan, U., Vyas, R., \& Giri, V. B. (2018). Two new species of the Ophisops microlepis (Squamata: Lacertidae) complex from northwestern India with a key to Indian Ophisops. Journal of Natural History, 52, 819-847. https://doi.org/10.1080/00222933.2018.1436203

Anso, J., Barrabe, L., Desutter-Grandcolas, L., Jourdan, H., Grandcolas, P., Dong, J., \& Robillard, T. (2016). Pixibinthus, a new cricket genus endemic in New Caledonia: phylogenetic study of a potential relict lineage from maquis minier vegetation. PLoS ONE, 11, e0150920. https://doi.org/10.1371/journal.pone.0150920.

Audacity Team (2016). Audacity(R): Free Audio Editor and Recorder [Computer application]. Version 2.0.0 retrieved January 12th 2016 from https://audacityteam.org/ [1].

Bhowmik, H.K. (1976). On the gryllid fauna (Gryllidae: Orthoptera) of the districts of the North Bengal, with description of three new species. Indian Museum Bulletin, 11, 42-48.

Bhowmik, H. K. (1985). Contribution to the gryllid fauna of the Western Himalayas (orthoptera: Gryllidae). Records of the Zoological Survey of India, 73, 67.

Biju, S. D., \& Bossuyt, F. (2005). A new species of frog (Ranidae, Rhacophorinae, Philautus) from the rainforest canopy in the Western Ghats, India. Current Science, 88, 175-178.

Biju, S. D., \& Bossuyt, F. (2009). Systematics and phylogeny of Philautus Gistel, 1848 (Anura, Rhacophoridae) in the Western Ghats of India, with descriptions of 12 new species. Zoological Journal of the Linnean Society, 155, 374-444. https://doi.org/10.1111/j.10963642.2008.00466.x

Biju, S. D., Bocxlaer, I., Giri, V. B., Loader, S. P., \& Bossuyt, F. (2009). Two new endemic genera and a new species of toad (Anura: Bufonidae) from the Western Ghats of India. BMC Research Notes, 2, 241. https://doi.org/10.1186/1756-0500-2-241

Chintauan-Marquier, I. C., Legendre, F., Hugel, S., Robillard, T., Grandcolas, P., Nel, A., Zuccon, D., \& Desutter-Grandcolas, L. (2016). Laying the foundations of evolutionary and systematic 
Cigliano, M.M., H. Braun, D.C. Eades \& D. Otte. Orthoptera Species File. Version 5.0/5.0. [Retrieved on April 04, 2019]. http://Orthoptera.SpeciesFile.org

Contreras, D., \& Chapco, W. (2006). Molecular phylogenetic evidence for multiple dispersal events in gomphocerine grasshoppers. Journal of Orthoptera Research, 15, 91-98. https://doi.org/10.1665/1082-6467(2006)15[91:MPEFMD]2.0.CO;2

Desutter, L. (1987). Structure et évolution du complexe phallique des Gryllidea (Orthoptera) et classification des genres néotropicaux de Grylloidea. 1re partie. Annales de la Société entomologique de France (N.S.), 23, 213-239.

Desutter-Grandcolas L. (2003). Phylogeny and the evolution of acoustic communication in extant Ensifera (Insecta, Orthoptera). Zoologica Scripta, 32, 525-561. https://doi.org/10.1046/j.1463-

Desutter-Grandcolas, L., \& Robillard, T. (2006). Phylogenetic systematics and evolution of Agnotecous in New Caledonia (Orthoptera : Grylloidea, Eneopteridae). Systematic Entomology, 31, 65-92. https://doi.org/10.1111/j.1365-3113.2005.00299.x

Desutter-Grandcolas, L., \& Jaiswara, R. (2012). Phalangopsidae crickets from the Indian Region (Orthoptera, Grylloidea), with the descriptions of new taxa, diagnoses for genera, and a key to Indian genera. Zootaxa, 3444, 1-39. http://dx.doi.org/10.11646/zootaxa.3948.3.5

Dong, J., Kergoat, G. J., Vicente, N., Rahmadi, C., Xu, S., \& Robillard, T. (2018). Biogeographic patterns and diversification dynamics of the genus Cardiodactylus Saussure (Orthoptera, Grylloidea, Eneopterinae) in Southeast Asia. Molecular Phylogenetics and Evolution, 129, 114. https://doi.org/10.1016/j.ympev.2018.06.001. 
546 Erixon, P., Svennblad, B., Britton, T., \& Oxelman, B. (2003). Reliability of Bayesian posterior probabilities and bootstrap frequencies in phylogenetics. Systematic Biology, 52, 665-673. https://doi.org/10.1080/10635150390235485

549 Folmer, O., Black, M., Hoeh, W., Lutz, R., \& Vrijenhoek, R. (1994). DNA primers for amplification of mitochondrial cytochrome $\mathrm{c}$ oxidase subunit I from diverse metazoan invertebrates. Molecular Marine Biology and Biotechnology, 3, 294-299.

552

553

554

555

556

557

558

559

560

561

562

563

564

565

566

567

568

569

570

Giri, V. B., Gower, D., \& Wilkinson, M. (2004). A new species of Indotyphlus Taylor (Amphibia: Gymnophiona: Caeciliidae) from the Western Ghats, India. Zootaxa, 739, 1-19. http://dx.doi.org/10.11646/zootaxa.739.1.1

Giribet, G., Carranza, S., Baguna, J., Riutort, M., \& Ribera, C. (1996). First molecular evidence for the existence of a Tardigrada plus arthropoda clade. Molecular Biology and Evolution, 13, 76-84. DOI: 10.1093/oxfordjournals.molbev.a025573

Giribet, G., Carranza, S., Riutort, M., Baguna, J., \& Ribera, C. (1999). Internal phylogeny of the Chilopoda (Myriapoda, Arthropoda) using complete 18S rDNA and partial 28S rDNA sequences. Philosophical Transactions of the Royal Society of London Series B-Biological Sciences, 354, 215-222. doi: 10.1098/rstb.1999.0373

Gorochov, A. V. (2002). Taxonomy of Podoscirtinae (Orthoptera: Gryllidae). Part 1: the male genitalia and Indo-Malayan Podoscirtini. Zoosystematica Rossica, 10, 346.

Gorochov, A. V. (2003). Taxonomy of Podoscirtinae (Orthoptera: Gryllidae). Part 2: Indo-Malayan and Australo-Oceanian Podoscirtini. Zoosystematica Rossica, 11, 274.

Gorochov, A. V. (2009). Sixth addition to the revision of Itarinae (Orthoptera: Gryllidae). Zoosystematica Rossica, 18, 222.

Gorochov, A. V. (2018). New or Little-Known Crickets of the Subfamily Phalangopsinae (Orthoptera, Gryllidae): 12. The Genus Parendacustes (Part 3) and Other Taxa. Entomological Review, 98, 170-183. https://doi.org/10.1134/s0013873818020069 
Haan, D. (1844). Verhandelingen over de Natuurlijke Geschiedenis der Nederlansche Overzeesche Bezittingen, 24, 235.

Hall, T. A. (1999). BioEdit: a user-friendly biological sequence alignment editor and analysis program for Windows 95/98/NT. Nucleic Acids Symposium Series, 41, 95-98.

Herrera, J. P. (2017). Testing the adaptive radiation hypothesis for the lemurs of Madagascar. Royal Society Open Science, 4, 161014. http://dx.doi.org/10.1098/rsos.161014

Hillis, D. M., \& Bull, J. J. (1993). An Empirical Test of Bootstrapping as a Method for Assessing Confidence in Phylogenetic Analysis. Systematic Biology, 42, 182-192. https://doi.org/10.1093/sysbio/42.2.182

Jaiswara, R., \& Desutter-Grandcolas, L. (2014). Revision of the genus Pteroplistes in India, with the description of two new species Pteroplistes kervasae Jaiswara, n. sp. and Pteroplistes masinagudi Jaiswara, n. sp. (Orthoptera, Grylloidea, Pteroplistinae). Zootaxa, 3814, 96-108. http://dx.doi.org/10.11646/zootaxa.3814.1.5

Jaiswara, R., Dong, J., \& Robillard, T. (2018). Revision of the genus Pseudolebinthus (Orthoptera, Gryllidae, Eneopterinae) with the description of a new species from Southeast Africa. Zootaxa, 4521, 265-274. https://doi.org/10.11646/zootaxa.4521.2.7

Jaiswara, R., Dong, J., Ma, L., Yin, H., \& Robillard, T. (2019). Taxonomic revision of the genus Xenogryllus (Orthoptera, Gryllidae, Eneopterinae). Zootaxa, 4545, 301-338. https://doi.org/10.11646/zootaxa.4545.3.1

Jamieson, B.G.M., Tillier, S., Tillier, A., Justine, J.-L., Ling, E., James, S., McDonald, K., \& Hugall, A.F. (2002). Phylogeny of the Megascolecidae and Crassiclitellata (Annelida, Oligochaeta): combined versus partitioned analysis using nuclear (28S) and mitochondrial (12S, 16S) rDNA. Zoosystema, 24, 707-734.

Jins, V. J., Sampaio, F. L., \& Gower, D. J. (2018). A new species of Uropeltis Cuvier, 1829 (Serpentes: Uropeltidae) from the Anaikatty Hills of the Western Ghats of India. Zootaxa, 4415, 401-422. http://dx.doi.org/10.11646/zootaxa.4415.3.1 
Kambhampati, S. (1995). A Phylogeny of Cockroaches and Related Insects Based on DNA-Sequence of Mitochondrial Ribosomal-Rna Genes. Proceedings of the National Academy of Sciences of the United States of America, 92, 2017-2020.

Katoh, K., Rozewicki, J., \& Yamada, K. D. (2017). MAFFT online service: multiple sequence alignment, interactive sequence choice and visualization. Briefings in Bioinformatics, 1-7. https://doi.org/10.1093/bib/bbx108

Kearse, M., Moir, R., Wilson, A., Stones-Havas, S., Cheung, M., Sturrock, S., Buxton, S., Cooper, A., Markowitz, S., Duran, C., Thierer, T., Ashton, B., Meintjes, P., \& Drummond, A. (2012). Geneious Basic: An integrated and extendable desktop software platform for the organization and analysis of sequence data. Bioinformatics, 28, 1647-1649. https://doi.org/10.1093/bioinformatics/bts199

Kuraku, S., Zmasek, C. M., Nishimura, O., \& Katoh, K. (2013). aLeaves facilitates on-demand exploration of metazoan gene family trees on MAFFT sequence alignment server with enhanced interactivity. Nucleic Acids Research, 41, 22-28. doi:10.1093/nar/gkt389

Kuramoto, M., \& Joshy, S. H. (2003). Two New Species of the genus Philautus (Anura: Rhacophoridae) from the Western Ghats, Southwestern India. Current Herpetology, 22, 51-60. https://doi.org/10.5358/hsj.22.51

Lanfear, R., Frandsen, P. B., Wright, A. M., Senfeld, T., \& Calcott, B. (2017). PartitionFinder 2: New methods for selecting partitioned models of evolution for molecular and morphological phylogenetic analyses. Molecular Biology and Evolution, 34, 772-773. https://doi.org/10.1093/molbev/msw260

Maroja, L.S., Andrés, J.A., \& Harrison, R.G. (2009). Genealogical Discordance and Patterns of Introgression and Selection Across a Cricket Hybrid Zone. Evolution, 63, 2999-3015. https://doi.org/10.1111/j.1558-5646.2009.00767.x

Mendelson, T. C., \& Shaw, K. L. (2005). Rapid speciation in an arthropod. Nature, 433, 375-376. https://doi.org/10.1038/433375a 
623 Miller, M. A., Schwartz, T., Pickett, B. E., He, S., Klem, E. B., Scheuermann, R. H., Passarotti, M.,

624

625

626

627

628

629

630

631

632

633

634

635

636

637

638

639

640

641

642

643

644

645

646

647

648 Kaufman, S., \& O'Leary, M. A. (2015). A RESTful API for Access to Phylogenetic Tools via the CIPRES Science Gateway. Evolutionary Bioinformatics Online, 11, 43-48. https://doi.org/10.4137/ebo.s21501

Nattier, R., Robillard, T., Desutter - Grandcolas, L., Couloux, A., \& Grandcolas, P. (2011). Older than New Caledonia emergence? A molecular phylogenetic study of the eneopterine crickets (Orthoptera: Grylloidea). Journal of Biogeography, 38, 2195-2209. https://doi.org/10.1111/j.1365-2699.2011.02563.x

Nattier, R., Grandcolas, P., Elias, M., Desutter-Grandcolas, L., Jourdan, H., Couloux, A., \& Robillard, T. (2012). Secondary Sympatry Caused by range expansion informs on the dynamics of microendemism in a biodiversity hotspot. PLoS ONE, 7, e48047. doi:10.1371/journal.pone.0048047.

Nattier, R., Grandcolas, P., Pellens, R., Jourdan, H., Couloux, A., Poulain, S., \& Robillard, T. (2013). Climate and soil type together explain the distribution of microendemic species in a biodiversity hotspot. PLoS ONE, 8, e80811. doi:10.1371/journal.pone.0080811.

Nguyen, L. T., Schmidt, H. A., von Haeseler, A., \& Minh, B. Q. (2015). IQ-TREE: a fast and effective stochastic algorithm for estimating maximum-likelihood phylogenies. Molecular Biology and Evolution, 32, 268-274. https://doi.org/10.1093/molbev/msu300

QGIS Development Team (2018). QGIS Geographic Information System. Open Source Geospatial Foundation Project. http://qgis.osgeo.org.

Raj, P., Dinesh, K. P., Das, A., Dutta, S. K., Kar, N. B., \& Mohapatra, P. (2018). Two new species of cricket frogs of the genus Fejervarya bolkay, 1915 (Anura: Dicroglossidae) from the Peninsular India. Records of the Zoological Survey of India, A Journal of Indian Zoology, 118, 1-21. https://doi.org/10.26515/rzsi/v118/i1/2018/121436

Ragge, D. R. (1955). The wing venation of the Orthoptera Saltatoria. British Museum Natural History, Londres, $v i,+159$. 
Rambaut, A., Suchard, M.A., Xie, D., \& Drummond, A.J. (2014). Tracer v1.6, Available from http://beast.bio.ed.ac.uk/Tracer

Ripplinger, J., \& Sullivan, J. (2008). Does choice in model selection affect maximum likelihood analysis? Systematic Biology, 57, 76-85. https://doi.org/10.1080/10635150801898920

Robillard, T., \& Desutter-Grandcolas, L. (2004a). High-frequency calling in Eneopterinae crickets (Orthoptera, Grylloidea, Eneopteridae): adaptive radiation revealed by phylogenetic analysis. Biological Journal of the Linnean Society, 83, 577-584. https://doi.org/10.1111/j.10958312.2004.00417.x

Robillard, T., \& Desutter-Grandcolas, L. (2004b). Phylogeny and the modalities of acoustic diversification in extant Eneopterinae (Insecta, Orthoptera, Grylloidea, Eneopteridae). Cladistics, 20, 271-293. https://doi.org/10.1111/j.1096-0031.2004.00025.x

Robillard, T. \& Desutter-Grandcolas, L. (2006). Phylogeny of the cricket subfamily Eneopterinae (Orthoptera, Grylloidea, Eneopteridae) based on four molecular loci and morphology. Molecular Phylogenetics and $\quad$ Evolution, 40, 643-661. https://doi.org/10.1016/j.ympev.2005.10.019

Robillard, T. (2006). Phylogenetic systematics of Pseudolebinthus, a new genus of Eneopterinae crickets (Orthoptera, Grylloidea, Eneopteridae) from south-east Africa. Systematic Entomology, 31, 671-683. https://doi.org/10.1111/j.1365-3113.2006.00347.x

Robillard, T., Grandcolas, P., \& Desuter-Grandcolas, L. (2007). A shift toward harmonics for highfrequency spectra in Eneopterinae crickets (Orthoptera, Grylloidea, Eneopteridae). Canadian Journal of Zoology, 85, 1264-1275. https://doi.org/10.1139/z07-106

Robillard, T., \& Ichikawa, A. (2009). Redescription of Two Cardiodactylus Species (Orthoptera, Grylloidea, Eneopterinae): The Supposedly Well-Known C. novaeguineae (Haan, 1842), and the Semi-Forgotten C. guttulus (Matsumura, 1913) from Japan. Zoological Science, 26, 878891. DOI: $10.2108 / z s j .26 .878$ 
Robillard, T., Montealegre-Z, F., Desutter-Grandcolas, L., Grandcolas, P., \& Robert, D. (2013). Mechanisms of high-frequency song generation in brachypterous crickets and the role of ghost frequencies. The Journal of Experimental Biology, 216, 2001-2011. https://doi.org/10.1242/jeb.083964

Robillard, T., Gorochov, A. V., Poulain, S., \& Suhardjono, Y. R. (2014). Revision of the cricket genus Cardiodactylus (Orthoptera, Eneopterinae, Lebinthini): the species from both sides of the Wallace line, with description of 25 new species. Zootaxa, 3854, 1-104. https://doi.org/10.11646/zootaxa.3854.1.1

Robillard, T., Dong, J. Legendre, F., \& Agauvoa, S. (2016). The brachypterous Lebinthini crickets from Papua New Guinea, with description of two new genera and four new species (Orthoptera: Gryllidae: Eneopterinae), in ROBILLARD T., LEGENDRE F., VILLEMANT C. \& LEPONCE M. (eds), Insects of Mount Wilhelm, Papua New Guinea. Muséum national d'Histoire naturelle, Paris, Mémoires du Muséum national d'Histoire naturelle, 209, 149-202. ISBN : 978-2-85653$784-8$

Robillard, T., \& Su, Y. N. (2018). New lineages of Lebinthini from Australia (Orthoptera: Gryllidae: Eneopterinae). Zootaxa, 4392, 241-266. https://dx.doi.org/10.11646/zootaxa.4392.2.2

Robin, V. V., Vishnudas, C. K., Gupta, P., Rheindt, F. E., Hooper, D. M., Ramakrishnan, U., \& Reddy, S. (2017). Two new genera of songbirds represent endemic radiations from the Shola Sky Islands of the Western Ghats, India. BMC Evolutionary Biology, 17, 31. https://doi.org/10.1186/s12862-017-0882-6

Ronquist, F., Teslenko, M., Mark, P. V. D., Ayres, D. L., Darling, A., Höhna, S., Larget, B., Liu, L., Suchard, M. A., \& Huelsenbeck, J. P. (2012). MrBayes 3.2: Efficient Bayesian Phylogenetic Inference and Model Choice Across a Large Model Space. Systematic Biology, 61, 539-542. https://doi.org/10.1093/sysbio/sys029 
698

699

700

701

702

703

704

705

706

707

708

709

710

711

712

713

714

715

716

717

718

719

720

721

Sadasivan, K., Ramesh, M. B., Palot, M. J., Ambekar, M., \& Mirza, Z. A. (2018). A new species of fan-throated lizard of the genus Sitana Cuvier, 1829 from coastal Kerala, southern India. Zootaxa, 4374, 545-564. https://doi.org/10.11646/zootaxa.4374.4.5

Saeed, A., \& Yousuf, M. (1990). New record of family Eneopteridae (Grylloidea: Orthoptera) from Pakistan. Pakistan Journal of Zoology, 22, 309.

Schneider, E. S., Römer, H., Robillard, T., \& Schmidt, A. K. D. (2017). Hearing with exceptionally thin tympana: Ear morphology and tympanal membrane vibrations in eneopterine crickets. Scientific Reports, 7, 15266. https://doi.org/10.1038/s41598-017-15282-z

Shapiro, L.H., Strazanac, J.S., \& Roderick, G.K. (2006). Molecular phylogeny of Banza (Orthoptera: Tettigoniidae), the endemic katydids of the Hawaiian Archipelago. Molecular Phylogenetics and Evolution, 41, 53-63. DOI: 10.1016/j.ympev.2006.04.006

Su, Y. N. (2016). A simple and quick method of displaying liquid-preserved morphological structures for microphotography. Zootaxa, 4208, 592-593. https://doi.org/10.11646/zootaxa.4208.6.6

ter Hofstede, H. M., Schoneich, S., Robillard, T., \& Hedwig, B. (2015). Evolution of a communication system by sensory exploitation of startle behavior. Current Biology, 25, 1-8. https://doi.org/10.1016/j.cub.2015.10.064

Trifinopoulos, J., Nguyen, L-T., von Haeseler, A., \& Minh, B.Q. (2016). W-IQ-TREE: a fast online phylogenetic tool for maximum likelihood analysis. Nuclei Acids Research, 44, W232-W235. doi: $10.1093 / \mathrm{nar} / \mathrm{gkw} 256$

Vicente, N. M., Olivero, P., Lafond, A., Dong, J., \& Robillard, T. (2015). Gnominthus gen.nov., a new genus of crickets endemic to Papua New Guinea with novel acoustic and behavioral diversity (Insecta, Orthoptera, Gryllidae, Eneopterinae). Zoologischer Anzeiger, 258, 82-91. https://doi.org/10.1016/j.jcz.2015.06.005 
722 Vicente, N. M, Kergoat, G. J., Dong, J., Yotoko, K., Legendre, F., Nattier, R. \& Robillard, T. (2017).

723 In and out of the Neotropics: historical biogeography of Eneopterinae crickets. Journal of 724 Biogeography, 44, 2199-2210. https://doi.org/10.1111/jbi.13026

725 
727 Table 1. Taxon and gene sampling. List of all Eneopterinae crickets and outgroups used in this study with current geographical distribution and GenBank

728 accession numbers. NA means missing data. Abbreviation of museums: IISERM- Indian Institute of Science Education and Research Mohali, Punjab, India;

729 MNHN-Muséum national d'Histoire naturelle, Paris, France; ZFMK- Zoologisches Forschungsinstitut und Museum Alexander Koenig, Bonn, Germany; ZIN-

730 Zoological Institute, Russian Academy of Sciences, S. Petersburg, Russia and ZSI- Zoological Survey of India, Kolkata, India.

\begin{tabular}{|c|c|c|c|c|c|c|c|c|c|}
\hline Species & Voucher / Lab code (type status) & $16 \mathrm{~S}$ & $12 S$ & $\mathrm{COI}$ & coll & Cytb & $18 \mathrm{~S}$ & $28 \mathrm{~S}$ & H3 \\
\hline Acheta domesticus (Linnaeus, 1758) & MNHN-EO-ENSIF3523 / Adom & AF248698 & ADZ97611 & JX897403 & JX897439 & AF248682 & AD18SITS1 & JX897465 & KR903150 \\
\hline Agnotecous meridionalis Desutter-Grandcolas, 2006 & MNHN-ENSIF-2772 / AmelP & JX897349 & JX897401 & JX897420 & NA & JX897311 & JX897579 & JX897488 & JX897553 \\
\hline Agnotecous meridionalis Desutter-Grandcolas, 2006 & MNHN-EO-ENSIF-2771 / AmePB & JX897350 & JX897402 & JX897410 & JX897442 & JX897313 & JX897597 & JX897489 & JX897550 \\
\hline Cardiodactylus novaeguineae (Haan, 1844) & MNHN-ENSIF2038 / C3CnoNC & JF972520 & JF972504 & MH662977 & MH662880 & JF972488 & JF972535 & MH663420 & NA \\
\hline Cardiodactylus novaeguineae (Haan, 1844) & MNHN-EO-ENSIF2030 / C2CnoPe & JF972521 & JF972506 & KU705563 & KU705551 & JF972490 & JF972537 & KR903500 & KR903151 \\
\hline Eneoptera guyanensis Chopard, 1931 & MNHN-EO-ENSIF2741 / Egu & AY905301 & AY905272 & JX897404 & KU705553 & AY905355 & AY905331 & KU705581 & JX897547 \\
\hline Eurepini sp. & MNHN-EO-ENSIF3155 / Eursp & KR903674 & KR903834 & KU705565 & KU705554 & KR903331 & KR904028 & KR903503 & KR903153 \\
\hline Gryllus bimaculatus De Geer, 1773 & MNHN-EO-ENSIF3524/3404 / Gbi & AF248685 & AY905292 & NA & KU705555 & AF248659 & AF514509 & KR903002 & KR903154 \\
\hline Indigryllus kudremu sp.nov. & ZSI / X3Xsp2 (AT) & KY595509 & KY595483 & KY646248 & MK761340 & AY905377 & AY905345 & KY605247 & KY646293 \\
\hline Lebinthus bitaeniatus Stål, 1877 & MNHN-EO-ENSIF4393 / L18LbiP1 & MK761250 & MK761274 & MK761331 & MK761341 & MK761353 & MK761293 & MK761313 & MK761370 \\
\hline Lebinthus bitaeniatus Stål, 1877 & MNHN-EO-ENSIF4394 / L28LbiP2 & MK761252 & MK761275 & MK761332 & NA & MK761354 & MK761294 & MK761314 & MK761371 \\
\hline Lebinthus luae Robillard \& Tan, 2013 & MNHN-EO-ENSIF2740 / L8LbiS1 (PT) & JF972524 & KR904017 & KU705567 & KU705557 & JF972493 & KR904199 & KR903665 & KR903321 \\
\hline Lebinthus luae Robillard \& Tan, 2013 & MNHN / L10LbiS3 & MK761253 & MK761276 & MK761333 & MK761342 & MK761355 & MK761295 & MK761315 & MK761372 \\
\hline Microbinthus santoensis Robillard, 2009 & MNHN-EO-ENSIF2484 / L7LsaPe & KU705528 & KU708011 & KU705569 & NA & KU705535 & KU705543 & KU705585 & KU705601 \\
\hline Microbinthus santoensis Robillard, 2009 & MNHN-EO-ENSIF2437 / LsaV (PT) & JF972527 & JF972511 & JX897405 & JX897441 & JF972495 & JF972542 & JX897467 & JX897548 \\
\hline Nisitrus vittatus (Haan, 1842) & MNHN-EO-ENSIF2742 / NviS & MH575026 & MH575158 & KU705572 & NA & MH662741 & AY905340 & KR903667 & JX897546 \\
\hline Pseudolebinthus gorochovi Robillard, 2018 & ZIN / X17PsMal1 (HT) & KY595508 & KY595472 & KY646231 & NA & NA & KY595511 & KY605231 & MK761373 \\
\hline Xenogryllus eneopteroides Bolívar, 1890 & MNHN-EO-ENSIF3159 / XenAC & KR903829 & KR904023 & KY646249 & NA & KR903490 & KR904205 & KR903670 & KR903328 \\
\hline Xenogryllus eneopteroides Bolívar, 1890 & MNHN-EO-ENSIF3442 / XenCl & MK761256 & MK761279 & NA & NA & NA & MK761298 & NA & MK761375 \\
\hline Xenogryllus eneopteroides Bolívar, 1890 & MNHN-EO-ENSIF3442 / XenGA & MK761257 & MK761280 & NA & NA & NA & MK761299 & MK761318 & MK761376 \\
\hline Xenogryllus maichauensis Gorochov, 1992 & ZFMK / XtrTh & MK761258 & NA & NA & NA & MK761357 & NA & NA & MK761377 \\
\hline Xenogryllus marmoratus (Haan, 1844) & MNHN-EO-ENSIF3161 / Xma2 & KR903830 & KR904024 & NA & MK761343 & KR903491 & KR904206 & NA & KR903329 \\
\hline Xenogryllus marmoratus (Haan, 1844) & MNHN-EO-ENSIF1599 / XmaCh1 & KY595510 & KY595484 & NA & MK761344 & KY646274 & KY595518 & KY605248 & KY646292 \\
\hline Xenogryllus marmoratus (Haan, 1844) & MNHN-EO-ENSIF1594 / XmaCh2 & MK761261 & MK761283 & NA & MK761345 & MK761360 & MK761302 & MK761320 & MK761379 \\
\hline Xenogryllus marmoratus (Haan, 1844) & MNHN-EO-ENSIF3562 / XmaCh3 & MK761262 & MK761284 & NA & MK761346 & MK761361 & MK761303 & MK761321 & MK761380 \\
\hline Xenogryllus mozambicus Robillard, 2019 & MNHN-EO-ENSIF1515 / XenMoz (PT) & MK761263 & MK761285 & MK761336 & NA & MK761362 & MK761304 & NA & MK761381 \\
\hline Xenogryllus transversus (Walker, 1869) & IISERM / Xtr715 & MK761264 & MK761286 & NA & NA & MK761363 & MK761305 & MK761322 & MK761382 \\
\hline
\end{tabular}


Xenogryllus transversus (Walker, 1869)

Xenogryllus transversus (Walker, 1869)

Xenogryllus transversus (Walker, 1869)

Xenogryllus ululiu Gorochov, 1990

Xenogryllus ululiu Gorochov, 1990

Xenogryllus ululiu Gorochov, 1990

Xenogryllus ululiu Gorochov, 1990

Xenogryllus ululiu Gorochov, 1990
IISERM / Xtr765

SERM / Xtr766

MNHN-EO-ENSIF87 / Xtrln

ZIN / X18XulV2

ZIN / X19XulSi

MNHN-EO-ENSIF4385 / X20XulCam1

ZIN / X21XulCam2

ZFMK / Xulth
MK761265 NA

MK761266 NA

JF972530

MK761268

MK761269

MK761270

MK761271

MK761272

\begin{tabular}{ll} 
NA & MK761337 \\
NA & NA \\
NA & KY646247 \\
MK761287 & NA \\
MK761288 & NA \\
MK761289 & NA \\
\hline
\end{tabular}

MK761290 NA

MK761291

NA
NA
MK761347
MK761348
MK761349
MK761350
MK761351
NA

MK761364

MK761365

NA

MK761367

NA

NA
MK761368
MK761306

MK761308

MK761309

MK761310

K761311

NA
MK761323

KY605246

MK761326

MK761327

MK761328

MK76132
MK761383

MK761384

KY646294

MK761386

MK761387

MK761388

MK761389

731 
Table 2. Characteristics of the eight DNA markers and primers used in this study and in the 736 phylogenetic analyses.

\begin{tabular}{|c|c|c|c|c|c|c|}
\hline & Gene & $\begin{array}{c}\text { Primer } \\
\text { name }\end{array}$ & Sequencing primers $\left(5^{\prime}-3^{\prime}\right)$ & Reference & $\begin{array}{l}\text { Annealing } \\
\text { temperature }\end{array}$ & Amplicon size \\
\hline \multirow{6}{*}{ 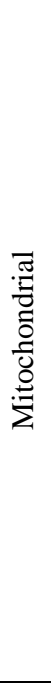 } & $\mathrm{CO} 1$ & $\begin{array}{l}\mathrm{L} 2 \\
\mathrm{H} 2\end{array}$ & $\begin{array}{c}\text { GCAACGATGATTATTTTCCACT } \\
\text { CCTGGTAAAATTAGAATGTAAACTTCTG }\end{array}$ & $\begin{array}{l}\text { Nattier et al. (2012), } \\
\text { modified from Folmer } \\
\text { et al. (1994) }\end{array}$ & $48-50^{\circ} \mathrm{C}$ & $\sim 750 \mathrm{bp}$ \\
\hline & \multirow[b]{2}{*}{$\mathrm{CO} 2$} & $\begin{array}{l}\operatorname{co} 2 \mathrm{a} \\
\operatorname{co} 2 \mathrm{e}\end{array}$ & $\begin{array}{l}\text { GGTCAAACAATTGAGTCTATTTGAAC } \\
\text { CCACAAATTTCTGAACATTGACCA }\end{array}$ & Shapiro et al. (2006) & $55^{\circ} \mathrm{C}$ & $\sim 400 \mathrm{bp}$ \\
\hline & & Rne & $\begin{array}{l}\text { TACWMAYCGWTTYCTTYTTGAAGGWC } \\
\text { CGACCTGGAGTTGCATCAG }\end{array}$ & $\begin{array}{l}\text { Nattier et al. (2012), } \\
\text { modified from } \\
\text { Contreras \& Chapco } \\
(2006) \\
\end{array}$ & $47^{\circ} \mathrm{C}$ & \\
\hline & Cytb & $\begin{array}{l}427 \mathrm{~F} \\
800 \mathrm{R}\end{array}$ & $\begin{array}{l}\text { YTWGTWCAATGARTMTGAGG } \\
\text { CCYARTTTATTAGGAATTGATCG }\end{array}$ & $\begin{array}{l}\text { Robillard \& Desutter- } \\
\text { Grandcolas (2006) }\end{array}$ & $48^{\circ} \mathrm{C}$ & $\sim 400 \mathrm{bp}$ \\
\hline & $12 \mathrm{~S}$ & $\begin{array}{l}\mathrm{F} \\
\mathrm{R}\end{array}$ & $\begin{array}{l}\text { TACTATGTTACGACTTAT } \\
\text { AAACTAGGATTAGATACCC }\end{array}$ & Kambhampati (1995) & $48^{\circ} \mathrm{C}$ & 400 bp \\
\hline & $16 \mathrm{~S}$ & $\begin{array}{l}\text { AG } \\
\text { BG }\end{array}$ & $\begin{array}{c}\text { CGCCTGTTTATCAAAAACATGT } \\
\text { AGATCACGTAAGAATTTAATGGTC }\end{array}$ & $\begin{array}{l}\text { Robillard \& Desutter- } \\
\text { Grandcolas (2006) }\end{array}$ & $55^{\circ} \mathrm{C}$ & $\sim 500$ bp \\
\hline \multirow{3}{*}{ 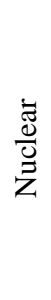 } & $\mathrm{H} 3$ & $\begin{array}{l}\text { HexAF } \\
\text { HexAR }\end{array}$ & $\begin{array}{l}\text { ATGGCTCGTACCAAGCAGACGGC } \\
\text { ATATCCTTGGGCATGATGGTGAC }\end{array}$ & Maroja et al. (2009) & $58^{\circ} \mathrm{C}$ & 330 bp \\
\hline & $28 \mathrm{SA}$ & $\begin{array}{l}\mathrm{C} 1 \\
\mathrm{D} 2 \mathrm{~b}\end{array}$ & $\begin{array}{l}\text { ACCCGCTGAATTTAAGCAT } \\
\text { GTTAGACTCCTTGGTCCGT }\end{array}$ & Jamieson et al. (2002) & $55^{\circ} \mathrm{C}$ & $\sim 400 \mathrm{bp}$ \\
\hline & $18 \mathrm{~S}$ & $\begin{array}{l}\mathrm{A} 2 \\
9 \mathrm{R}\end{array}$ & $\begin{array}{c}\text { ATGGTTGCAAAGCTGAAAC } \\
\text { GATCCTTCCGCAGGTTCACCTA }\end{array}$ & $\begin{array}{l}\text { Giribet et al. (1999) } \\
\text { Giribet et al. (1996) }\end{array}$ & $52^{\circ} \mathrm{C}$ & $\sim 650 \mathrm{bp}$ \\
\hline
\end{tabular}


Table 3. Measurements of Indigryllus kudremu sp. nov.

\begin{tabular}{|c|c|c|c|c|c|c|c|c|c|c|c|}
\hline & BL & PronL & & PronW & & FWL & FWW & FIIIL & & FIIIW & \\
\hline Holotype male & 21.2 & 3.1 & & 4.9 & & 10.3 & 5.0 & 18.4 & & 4.5 & \\
\hline Male paratype & 22.3 & 2.9 & & 4.8 & & 10.7 & 5.0 & 18.6 & & 4.9 & \\
\hline (Male mean) & $(21.8)$ & (3) & & (4.9) & & $(10.5)$ & $(5.0)$ & $(18.5)$ & & $(4.7)$ & \\
\hline \multirow[t]{3}{*}{ Female allotype } & 18.8 & 3.5 & & 4.8 & & 4.2 & 3.4 & 18.3 & & 5.0 & \\
\hline & \multirow[t]{2}{*}{ TIIIL } & \multicolumn{6}{|l|}{ TIIIs } & \multicolumn{3}{|c|}{ TaIIIs } & \multirow[t]{2}{*}{ OL } \\
\hline & & Ias & Ibs & & Oas & & Obs & Ids & Ods & Ols & \\
\hline Holotype male & 17.9 & 9 & 11 & & 12 & & 10 & 0 & 3 & 3 & - \\
\hline Male paratype & 18.5 & 10 & 7 & & 18 & & 10 & 0 & 4 & 3 & - \\
\hline (Male mean) & (18.2) & (10) & (9) & & (15) & & (10) & (0) & (4) & (3) & - \\
\hline Female allotype & 18.7 & 8 & 12 & & 15 & & 13 & 1 & 6 & 3 & 10.5 \\
\hline
\end{tabular}




\section{Figure legends}

Figure 1. Indigryllus kudremu sp. nov.: male in dorsal (A) and lateral (B) views, female in dorsal (C) and lateral (D) views. Scale bar: $5 \mathrm{~mm}$.

Figure 2. Head view: Indigryllus kudremu sp. nov. in dorsal (A), facial (B) and lateral views (C); Xenogryllus eneopteroides in dorsal (D), facial (E) and lateral views (F). Scale bar: $1 \mathrm{~mm}$.

Figure 3. Indigryllus kudremu sp. nov.: male forewing venation (A-B) and terminologies used in the systematic part, female forewing venation (C). Scale bars: $1 \mathrm{~mm}$.

Figure 4. Indigryllus kudremu sp. nov..: male genitalia in dorsal (A), ventral (B) and lateral (C) views, detail of pseudepiphallic parameres in ventral view (D). Scale bar: $1 \mathrm{~mm}$.

Figure 5. Right pseudepiphallic lophi of male genitalia in dorsal view: (A) Indigryllus kudremu sp. nov.; (B) Xenogryllus eneopteroides; (C) Xenogryllus transversus and (D) Pseudolebinthus africanus. Symbols: Preapical hook-like expansion figured in gray or with a black arrow; dotted parts represent membranous areas; thin lines represent folds and reliefs in sclerites. Scale bar: $1 \mathrm{~mm}$.

Figure 6. Apex of female ovipositor: (A) Indigryllus kudremu sp. nov. and (B) Xenogryllus eneopteroides. Apex of female subgenital plate and base of ovipositor in ventral view: (C) Indigryllus kudremu sp. nov. and (D) Xenogryllus eneopteroides. Female copulatory papilla: (E-G) Indigryllus kudremu sp. nov. and (H-I) Xenogryllus eneopteroides.

Figure 7. Bayesian Inference tree of Xenogryllini tribe based on the concatenated dataset of eight genetic markers. ML bootstrap (BS) and Bayesian posterior probability (PP) support values are indicated for each node on the right; clades not recovered by the BI analysis are indicated by a symbol *. Clades corresponding to species are shaded with a colour scale. Represented species (from top to bottom): Agnotecous sarramea, Lebinthus bitaeniatus, Xenogryllus transversus.

Figure 8. Distribution map of the species belonging to the Xenogryllini tribe. Each colour point represents a collecting locality based on recent revision studies of Xenogryllus (Jaiswara et al., 2019) and Pseudolebinthus (Jaiswara et al., 2018). Map designed using the software QGIS (QGIS Development Team (2018). 


\section{List and legend of supporting information}

774

775 S1. Sequence alignment of the concatenated molecular genetic markers generated by Geneious.

776 S2. Results of preliminary maximum likelihood (ML) analyses for each genetic marker.S3. Best-fit 777 models of sequence evolution and partitioning schemes selected with PartitionFinder.

778

779 S4. Original output results of Bayesian inference (BI) and Maximum likelihood (ML) analyses for 780 concatenated dataset.

781 


$$
\text { \$? }
$$


$784 \quad$ Fig.2
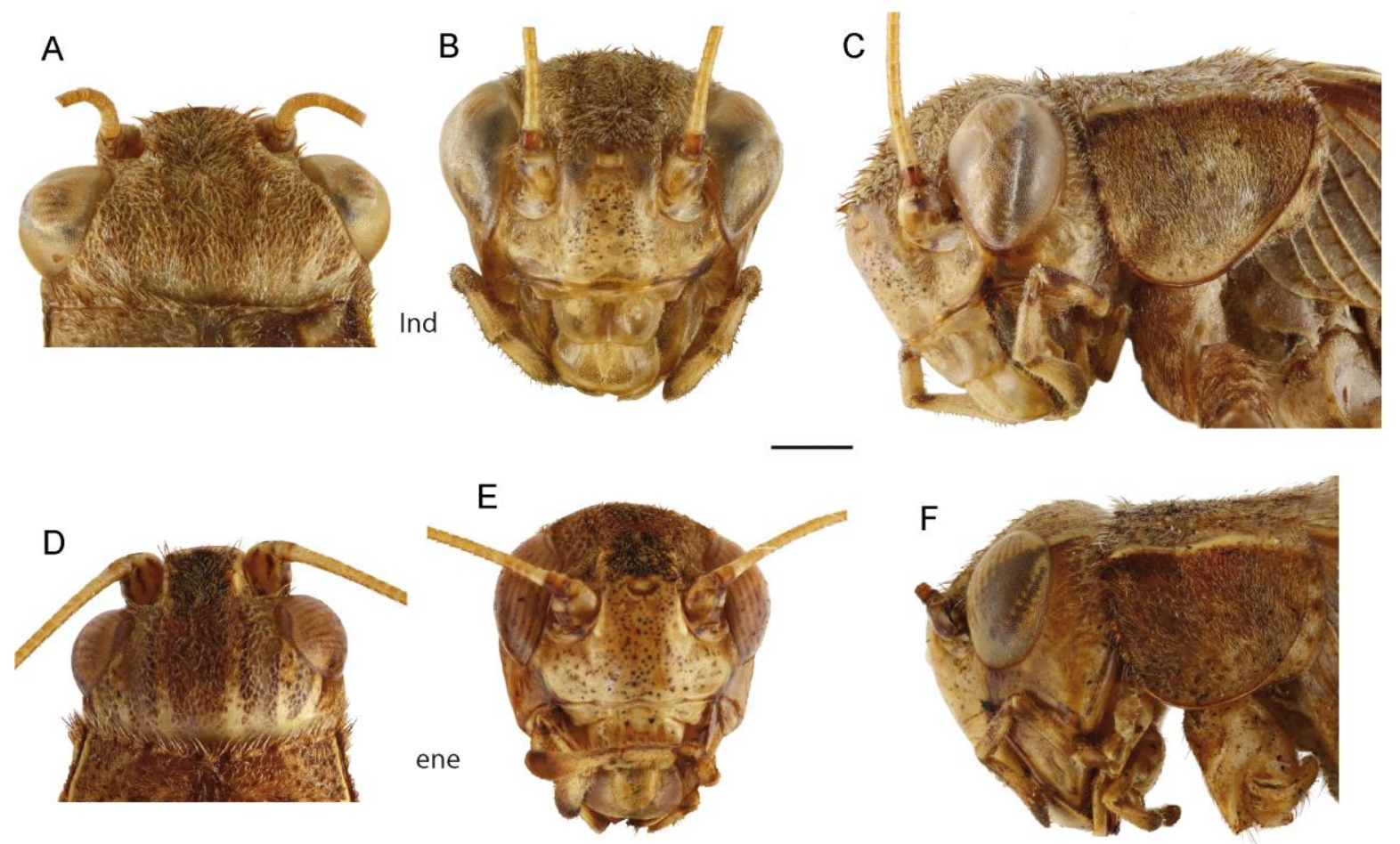

785

786

787 
Fig.3

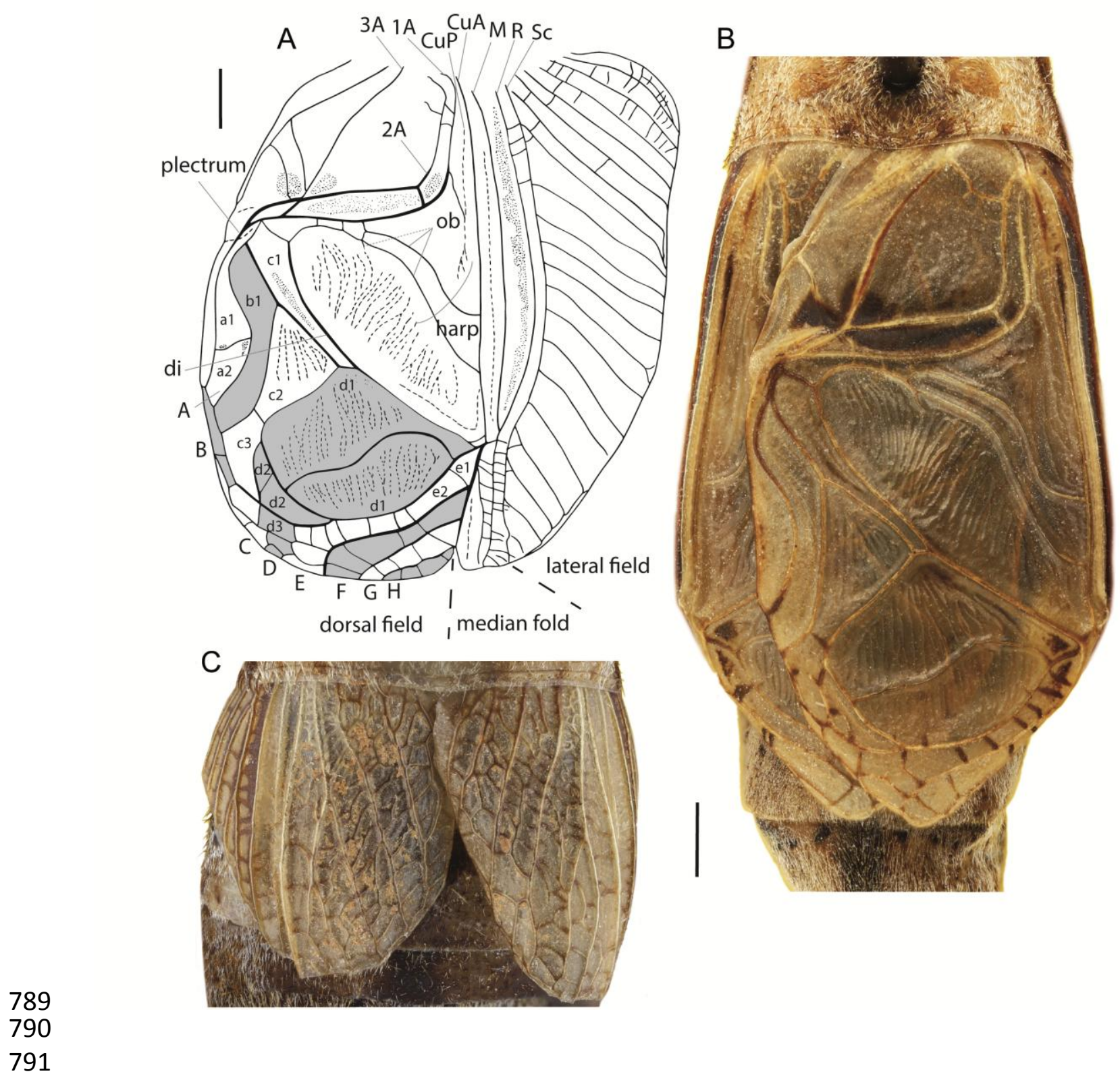


$792 \quad$ Fig.4
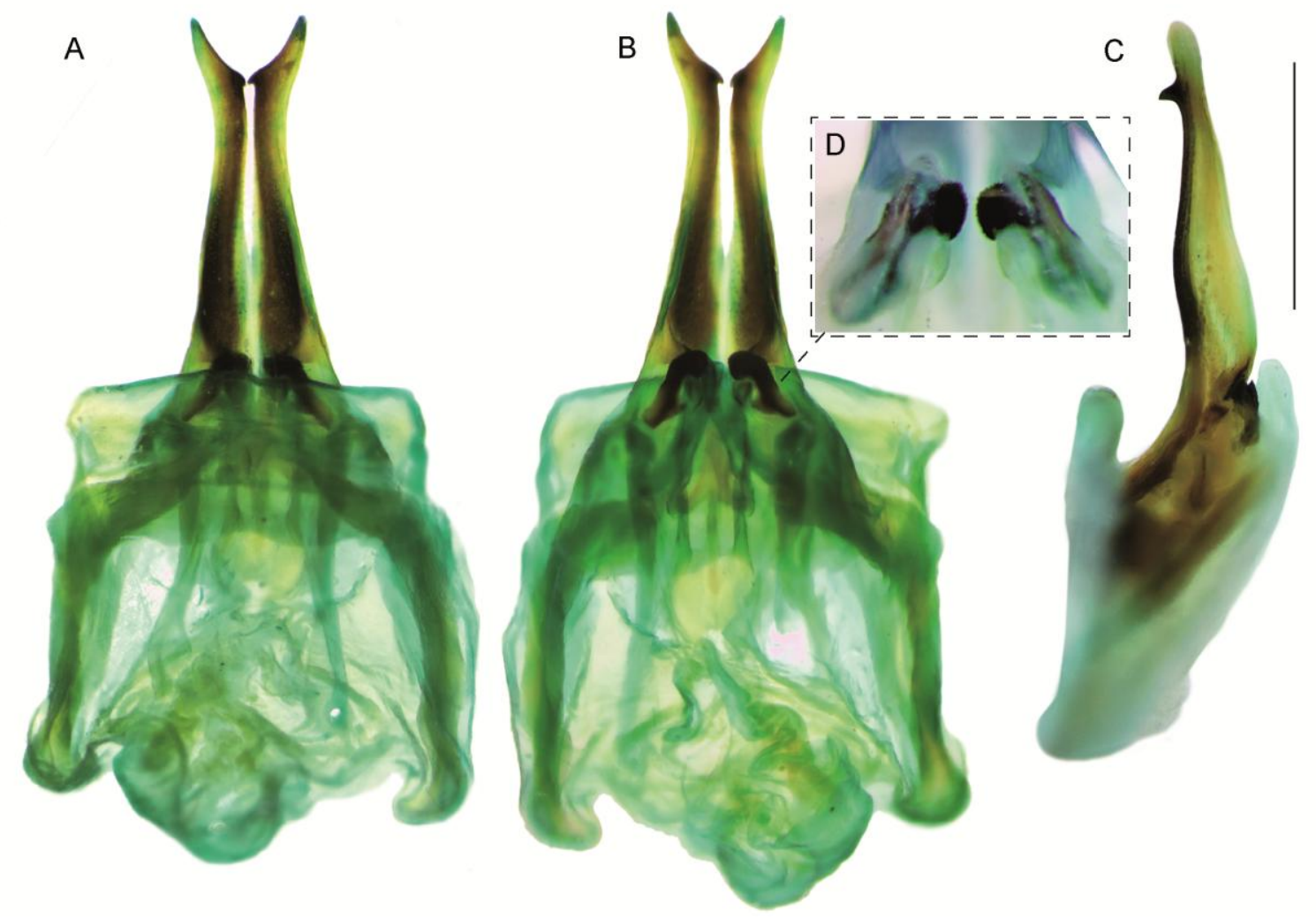

793
794 
$795 \quad$ Fig.5
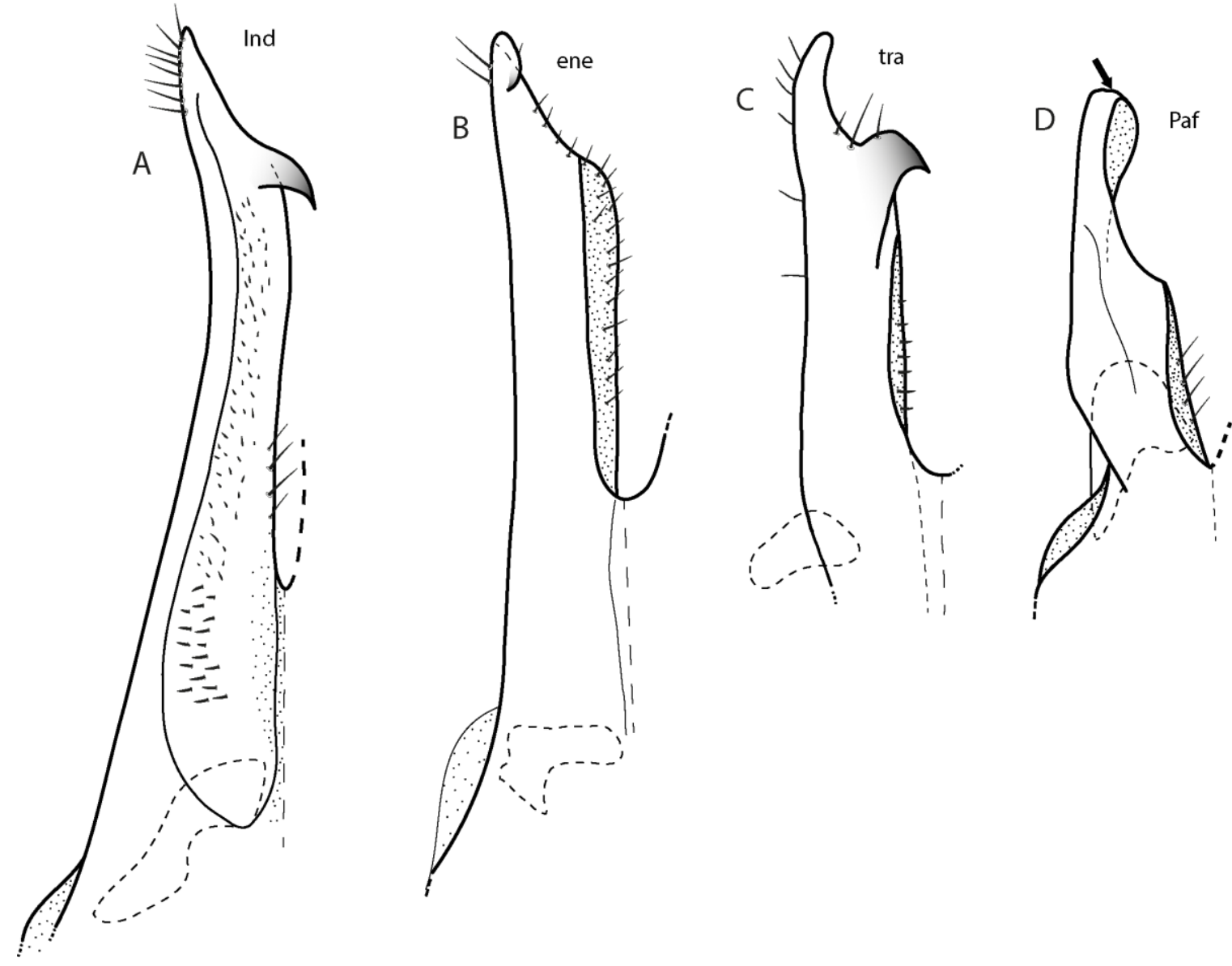

796
797 
$798 \quad$ Fig.6

799

800

A
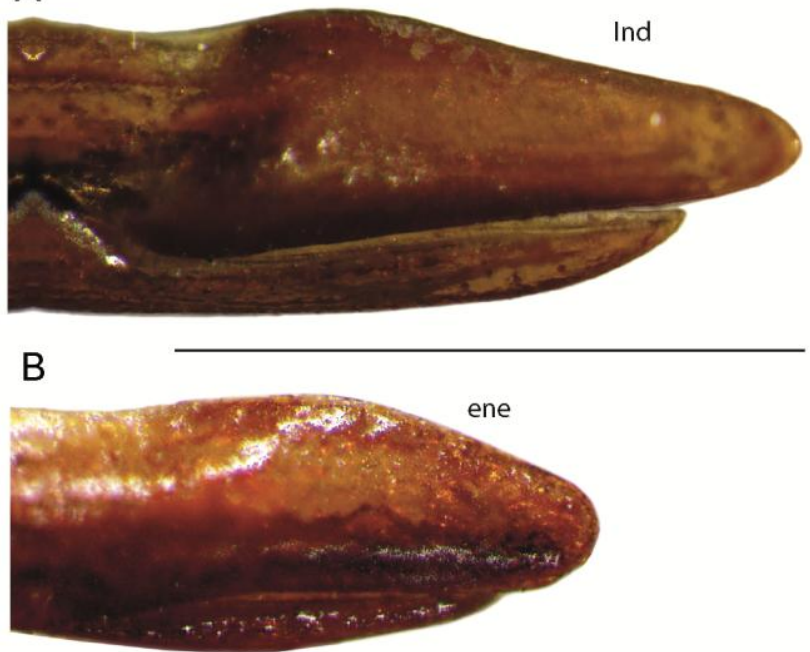

E

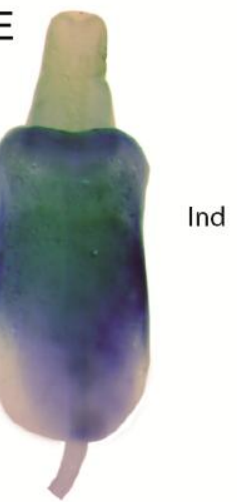

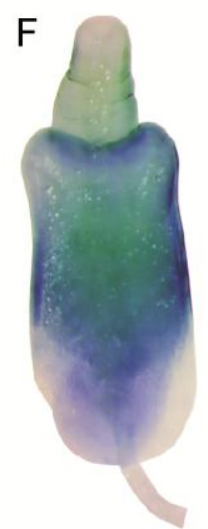

G

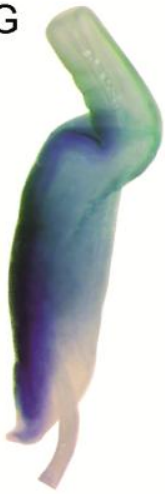

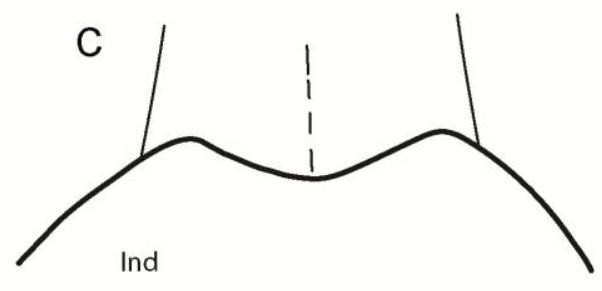
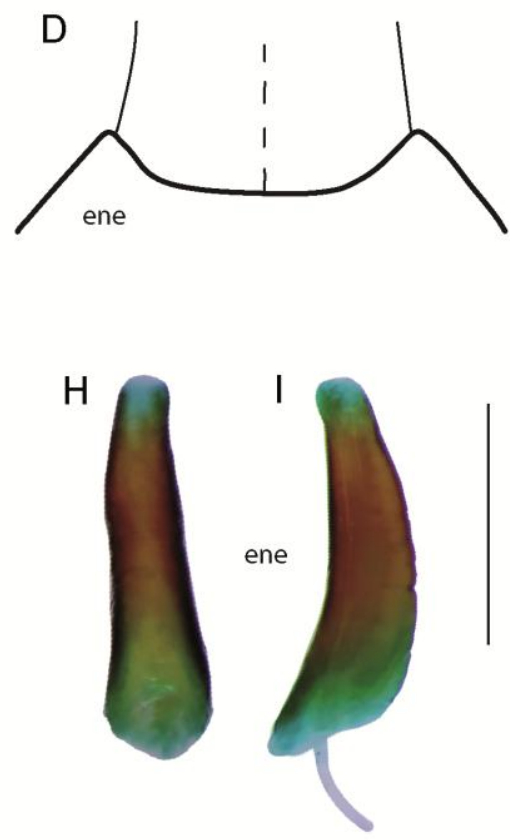

801

802

803 
Fig.7

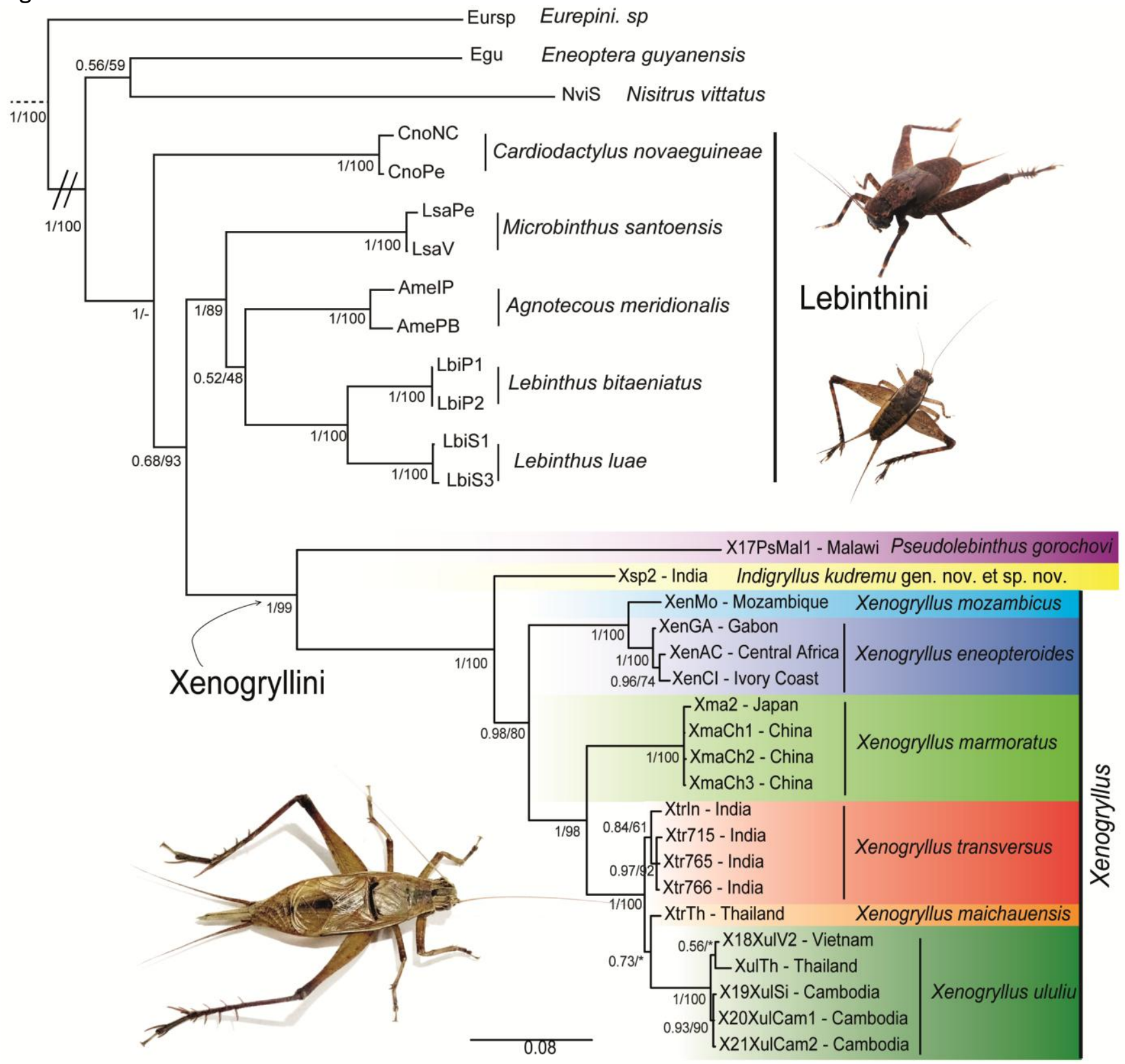




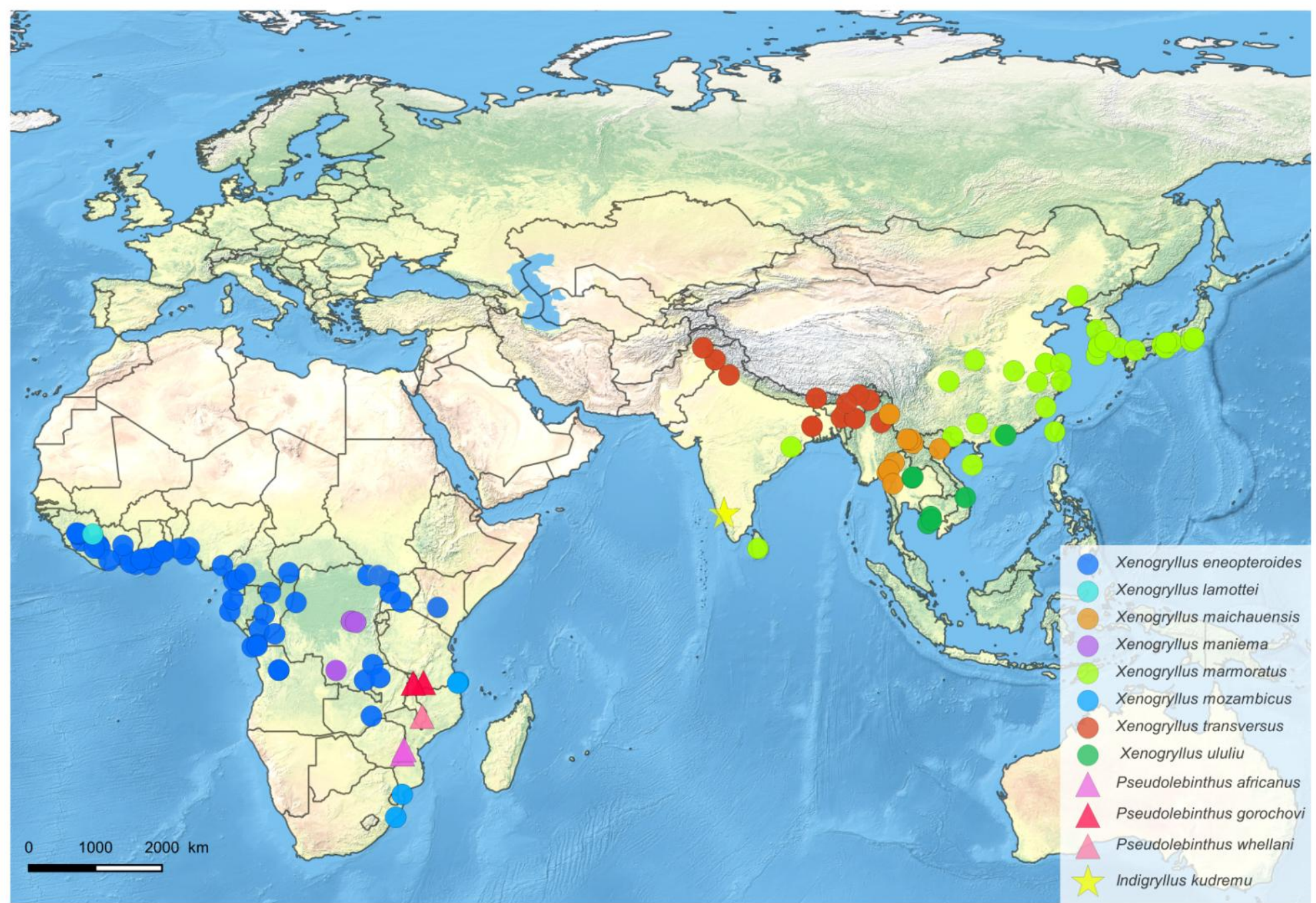

